\title{
Über die ultravisible Form des Tuberkelbazillus.
}

\author{
Von \\ Keiiti Kimura. \\ (木 村圭一) \\ (Aus der Medizinischen Klinik von Prof. Dr. T. Kumagai, \\ Tohoku-Universität zu Sendai.)
}

\section{Einleitung.}

Seit der Entdeckung der Tuberkelbazillen durch Robert Koch haben viele Forscher sie morphologisch untersucht. Bisher sind verschiedene Auffassungen über ihren Plcomorphismus mitgeteilt worden.

Spengle r ${ }^{1)}$ (1905) entdeckte im Sputum eine sehr kurze, körnerartige Form des Tuberkelbazillus und gab ihr den Namen Splitter. Später wies $\mathrm{Mu} \mathrm{ch}^{2)}$ mit seiner eignen Färbungsmethode nicht-säurefestes, granuläres Virus bei der Lungenperlsucht der Rinder nach und stellte es experimentell als eine Art Tuberkelbazillen fest. Im Jahre 1910 teilte F ontés ${ }^{33}$ mit, dass er in der angeschwollenen Milz solcher Tiere, die er einen Monat vorher mit durch den Berkefeld-Filter filtriertem Eiter geimpft hatte, grampositive Granula bemerkt habe; damit stellte er das Problem des filtrierbaren Virus der Tuberkelbazillen zum ersten Male auf. Nachdem aber die Nachprüfung durch Philibert ${ }^{4}$ (1912) negativ ausgefallen war, liess man dieses Problem Jahre lang unberücksichtigt. Erst im Jahre 1923 bestätigte Vaudremer ${ }^{5)}$ durch Experiment die Mitteilung von Fontés. Das hat die Forscher wieder auf das Problem aufmerksam gemacht. Seitdem sind aus vielen Ländern verschiedene Berichte darüber veröffentlicht worden.

Vau d re me r filtrierte die homogene Kultur der auf Glyzerinkartoffel kultivierten granulären Tuberkelbazillen durch Chamberland L3 und stellte dabei den Übergang der Granula ins Filtrat fest, in dem nach seiner Mitteilung sich die Granula niederschlagen und wachsen. Weiter machten Handuroy und Vaudremer ${ }^{6)}$ einen Versuch mit den in Peptonglyzerinwasser und auch in Glyzerinkartoffel kultivierten Bazillen und fanden im Filtrat schwach säurefeste Granula. Da- 
her behaupteten sie, dass die Muchschen Granula filtrierbar wären. Valtis ${ }^{i)}$ (1924) stellte einen Versuch mit dem Filtrat aus tuberklösem Sputum durch Chamberland L2 an. Nach seiner Mitteilung ist zwar eine direkte Kultur des Filtrats unmöglich, aber bei der Überimpfung auf Meerschweinchen kann man Tuberkelbazillen beobachten.

Weiter erzeugten Vannucci ${ }^{8)}$ (1925) und Veber ${ }^{97}$ (1926), jener mit dem Filtrat von Eiter und dieser mit dem von Pneumothoraxexsudat durch Chamberland L2, bei Tieren Tuberkulose. Arloing, Dufourt u. Malartre ${ }^{10)}$ (1925) haben ein Filtrat aus dem Organ tuberkulöser Meerschweinchen, Néli s' ${ }^{11}$ (1927) aus tuberkulösem Harn, Valtis, Nègre, Boquet u. Certoncin $y^{12}$ (1927) aus Tuberkelbazillenkultur hergestellt, und sie alle haben im Organ desjenigen Tiers, das mit dem betreffenden Filtrat geimpft wurde, säurefeste Stäbchen gefunden. Togoun of $f^{13)}$ (1927) berichtet: er habe mit dem Filtrat aus tuberkulösem Sputum Versuche angestellt und bei Tieren Anschwellungen sowohl der Bronchialdrüsen als auch des Retikuloendothelialsystems der Milz beobachtet und darin, wenn auch nicht züchtbar, eine Anzahl säurefester Bazillen entdeckt. Er bemerkte noch die Entstehung eines Primärkomplexes in der Vorkammer des Auges, in die man das Filtrat geimpft hatte, aber keine Virulenzsteigerung durch Tierpassage. Ferner gewannen Bonciu und Jonesc $\left.{ }^{14}\right)(1928)$ positive Ergebnisse mit dem tuberkulöser Kranken, ebenso Rabinowitsch-Kempne ${ }^{15)}$ (1928) mit dem Filtrat aus tuberkulösem Material, welches zwar nicht durch den Chamberland filter, wohl aber durch den Membranfilter hergestellt war, Sweany ${ }^{16}$ (1928) mit einem tuberkulösen Herd und Priboiano u. Laco m me $\mathrm{e}^{17)}$ (1929) mit der Milch tuberkulöser Frauen. Weiter seien unter denen, die das Vorhandensein des filtrierbaren Virus von Tuberkelbazillen bejahen, noch folgende Autoren genannt. Isabolinski u. Gitowitsch, ${ }^{18)}$ Vascellariu. Giuseppe, ${ }^{19}$ Sanarelli u. Alessandrini, ${ }^{20}$ Sanctis Monaldi, ${ }^{21)}$ Cuturi u. Lanza ${ }^{22}$ u. a.

Nach Lucksch ${ }^{23)}$ (1930) gibt es im Sputum Tuberkulöser oft Granula, und wenn solches Sputum mit Natronlauge neutralisiert und durch den Berkefeldfilter filtriert wird, gehen die Granula ins Filttrat über, aber Chamberland L3 passieren kleine Granula nur sehr selten. Er behauptet, dass man durch Injektion dieses Filtrats Anhäufung: atypischer granulärer Bazillen bei Tieren beobachten kann, dass aber dadurch keine typische Tuberkulose entsteht.

Calmette ${ }^{24) 55}$ der mit seinen Schülern immer das Vorhandensein des ultravisiblen, filtrierbaren Virus behauptete, veröffentlichte 1930 seine zusammenfassende Meinung darüber. Nach dem Gesamtergebnis der Calmetteschen Versuche besteht das ultravisible Tuberkulosevirus in Organen, Eiter, Sputum, Blut, Harn, Milch, Exsudat, 
in den Bazillen junger Kulturen usw, Dieses Virus passiere auch die Plazenta und infiziere oder vergifte oft den Foetus. Merkwürdigerweise bleibt es gern im Lymphsystem, besonders in den Bronchialund Mesenterialdrüsen. Dabei sei der Hauptbefund Lymphdrüsenschwellung, aber ohne Tuberkeln oder einen Primärherd. Auch werde kein echter tuberkulöser Herd gefunden. Diese Art Virus nehme an Virulenz zu und bringe bei den Tieren Tuberkulinempfindlichkeit hervor. Daraufhin hat Calmette vorgeschlagen, die Veränderungen durch die gewöhnlichen Tuberkelbazillen Bazillose, die im allgemeinen akuten, aber relativ leichten Veränderungen durch das ultravisible, filtrierbare Virus präbazilläre Granulämie zu nennen. Später (1930) konnten Calmette u. Valti ${ }^{26)}$ und Valtis u. Saenz $z^{27)}$ Tuberkelbazillen unmittelbar aus dem Filtrat auf dem von ihnen eigens dazu hergestellten vitaminhaltigen Nährboden kultivieren.

Ninni ${ }^{28229}(1930)$ impfte das Filtrat in die Halsdrüsen der Tiere und bemerkte beim Filtrat von 8tägiger Kultur säurefeste Bazillen, bei dem von 34-64tägiger Kultur dagegen keine. Weiter spritzte er 1932 nach seiner Methode das Filtrat in die Halsdrüsen, schlachtete das Tier nach 14 Tagen, behandelte dessen Organe mit Schwefelsäure, kultivierte sie auf Löwensteinschem Nährboden und entdeckte da nach 12-14 Tagen eine Kolonie von Tuberkelbazillen. Er behauptete, dass er den Nachweis säurefester Bazillen dadurch leichter gemacht habe, dass er das Filtrat intraperitoneal impite und zugleich eine Kalziumphosphatlösung einspritzte. Auf diese Weise soll man schon in 2-4 Tagen ein positives Ergebnis gewinnen können.

Lanza $a^{30)}$ (1931) fand im Ascites eines rheumatischen, mitralinsuffizienten Kranken ultravisibles Virus. $\mathrm{Pu} \mathrm{ca}^{31)}(1932)$ filtrierte 47 Proben desLiquor cerebrospinalis der.Dementia praecox und entdeckte bei 7 Proben von damit geimpften Tieren säurefeste Bazillen.

Obigen Forschern mit positivem Ergebnis stehen nun aber nicht wenige gegenüber, die es bestreiten. Fessle ${ }^{32}$ (1926) prïfte die Kulturmethode Vaudremers nach und bemerkte zwar auf dem Boden der Röhre Gebilde, wie sie Vaudremer beobachtet hatte, fand aber, dass auch auf nicht kultiviertem Nährboden ein ganz gleicher Niederschlag entsteht. Wenn die Tiere damit geimpft werden, hat man, mit nur einer einzigen Ausnahme, fast durchweg negative Ergebnisse; die dabei beobachteten tuberkulösen Veränderungen stammen vermutlich von einer selten vorhandenen Spontaninfektion her. Dadurch kam Fessler dazu, Vaudremers Behauptung zu bestreiten. Auch Nakajo (1928) führte sie auf Eiweisfällung zurïck.

Monte martin $i^{34}$ (1925) behauptet : man sieht zuweilen an Lymphdrüsen, Milz, Lunge usw. verdächtige Herde, die aber weder histologisch noch kulturell tuberkulös sind, sondern bloss Veränderun- 
gen infolge der Tuberkulininjektion. Betten $\mathrm{i}^{35}$ (1931) sowie $\mathrm{Ca}$ puani ${ }^{36}$ (1931) stimmten dieser Meinung bei. Cooperu. Petrof f ${ }^{37)}$ (1928) fanden bei $36 \%$ mit Filtrat geimpfter Meerschweinchen säurefeste Substanz, aber sie wiesen sie auch bei 33\% normaler Meerschweinchen nach. Die Kachexie führen sie auf Intoxikation durch fremdes Eiweiss zurück. Lindemann und $\mathrm{Li}^{38}(1928)$ bemerkten bei 5 unter 41 mit Filtrat geimpften Tieren säurefeste Stäbchen, die ohne weiteres für Tuberkelbazillen zu halten sie aber für wenig begründet erachten. Morosow $a^{399}$ (1929) bestritt auch das Vorhandensein filtrierbaren Virus', weil die Tuberkulinreaktion auch beim Filtrat gekochter Sputa positiv war. Nach Thompson u. Frobischer ${ }^{40)}$ (1928) hat man den nämlichen Befund bei den mit Filtrat geimpften Tieren sowie auch bei den mit gekochtem Filtrat geimpften. Sie bemerkten bei $\frac{1}{3}$ der Tiere säurefeste Gebilde.

Löwenstein u. Singe $\mathrm{r}^{412}$ (1929) behaupteten, dass es zweifellos möglich sei, an tuberkulösem Material, bei dem mikroskopisch keine Bazillen zu finden seien, durch Tierversuch oder Kultur doch Tuberkelbazillen nachzuweisen, aber sie behaupteten weiter, dass die positiven Ergebnisse von nur 1-2\% bei der französischen Schule von der Unvollkommenheit des Filters herrührten und daher schwerlich als Beweis für die Existenz filtrierbaren Tuberkulosevirus' gelten könnten. Selter u. Blumenber ${ }^{42)}$ (1929) leugneten überhaupt das Bestehen des Tuberkuloseultravirus, und zwar aus folgendem Grunde. Man sehe zwar häufig Lymphdrüsenanschwellung, aber sie sei vorübergehend und nicht pathologisch. Es sei unmöglich, säurefeste oder sporoide Gebilde kulturell oder durch Tierexperiment als Tuberkelbazillen nachzuweisen. Solche säurefeste Substanz wurde von ihnen bei $32 \%$ normaler Meerschweinchen nachgewiesen.

Lange u. Clauber. ${ }^{43}$ (1929) bestritten das Vorhandensein der von Petroff behaupteten saprophytischen säurefesten Bazillen in den Meerschweinchenorganen, da er säurefeste Bazillen nur selten bei mit Filtrat geimpften Tieren, bei normalen Meerscnweinchen aber niemals finden konnte. Er vermutete, dass die fraglichen Bazillen avirulente Varianten oder eine verkümmerte Form von Tuberkelbazillen wären.

Kirchner ${ }^{43)}$ (1930) stellte eine Mischkultur von Tuberkelbazillen und anderen Mikroorganismen her und erwartete nun von dern so gewonnenen Filtrat, dass vielleicht durch Symbiose mit anderen Mikroorganismen filtrierbares Tuberkulosevirus entstünde, aber das Ergebnis blieb negativ. Er bemerkte auch, dass sich intrakutane Tuberkulinreaktion bei der Injektion von Timotheebazillen mit Tuberkulin oder des Ölextrakts von Tuberkelbazillen positiv erwies. Le usden $^{45)}$ Experiment (1930) war auch negativ. Schmidt t5) (1931) hielt die direkte Züchtung des Filtrats auf den Nährboden von Calmette, 
Valtis u. Saenz für unmöglich. Beim Tierexperimente bemerkte er kein filtrierbares Virus. Alle Versuche von Petragnani ${ }^{47}$ (1931) endeten negativ. Auch Szüle $e^{48)}$ (1931) bestritt das Bestehen filtrierbaren Virus'. Denn erstens entstehe Lymphdrüsenanschwellung durch fremdes Eiweiss und auch durch Tuberkulin, zweitens sei die Tuberkulinallergie nichts anderes als Parallergie, und drittens habe sich die Kultur immer negativ erwiesen. Pinnexu. Voldrich ${ }^{49}$ wiesen darauf hin, dass auf festem Nährboden kultiviertes Filtrat keine Veränderungen an Tieren hervorbrachte, hingegen Filtrat auf flüssigem Boden kultivierter Bezillen deutliche Kachexie. Aus ihre1 Wärmeresistenz und ihrer Unfähigkeit zur Tierpassage schliessen sie dass die Ursache davon keine Mikroorganismen, sondern irgend ein Gift sein muss.

Zum Schluss sei noch schnell ein Blick auf die japanische Literatur geworfen. Yoshinaga u. Endo (1926) bemerkten tuber. kulöse Veränderungen bei $\frac{1}{3}$ der mit Filtrat geimpften Tiere. Miyamoto $^{512}(1928)$ und Nakaga wa $a^{52)}$ (1932) berichteten positive Ergebnisse. Nakajo ${ }^{33)}$ (1929), Maeda u. Sumikawa $a^{53)}(1927)$ und Nishimoto ${ }^{54}$ (1928) bestritten sie. Tomomatsu ${ }^{\text {i5) }}$ (1932) entdeckte biologisch kein ultravisibles, filtrierbares Tuberkulosevirus, hält e६ aber für möglich, dass die kleinsten sichtbaren Bazillen, wenn auch sehr selten, filtrierbar sind.

\section{Methodik.}

\section{Prüfung des Filters.}

Als Filter verwendete ich Chamberland L3. Zuerst musste e؛ genau geprüft werden. Aus $2 \mathrm{mg}$ bazillus prodigiosus bereitete icl mit $10 \mathrm{ccm}$ physiologischer Kochsalzlösung eine Emulsion. Diest filtrierte ich unter negativem Druck von je 10,20,30 und $50 \mathrm{~cm} \mathrm{H} \mathrm{H}_{\varepsilon}$ 10-30 Minuten lang. Dadurch stellte ich fest, dass die Kultur des sc gewronnenen Filtrats auf Agar steril war. Das Filter wurde vor je. dem Gebrauch etwa 15 Stunden lang gegliiht, nach der Abkühlung mit aqua destillata gewaschen und überdies noch durch trockene Hitz bei $150^{\circ}$ sterilisiert.

Ausgangsmaterial.

1. Frisch kultivierte Tuberkelbazillen:

a. Typus humanus

1 Monat alte Kultur auf $\mathrm{Hohnscher}$ Nährboden.

b. Typus bovinus

1 Monat alte Kultur auf Gingkoeier nährboden (nach $S$ u z uki ${ }^{56)}$ ). 
2. Lange Zeit hindurch kultivierte Tuberkelbazillen:
a. Typus humanus
2 Monate alte Kultur auf Locke-
b. Typus humanus m a n n schem flüssigem Nährboden.
c. Typus humanus
4 Monate alte Kultur auf Gingkoeier- nährboden und
1 Jahr alte Kultur auf $\mathrm{Hohnschem}$ Nährboden.

3. Tuberkelbazillen zur Zeit des Wachstumsbeginns:
a. Typus humanus
1-3 Tage alte Kultur auf Gingkoeier- nährboden,
b. Typus humanns
5-10 Tage alte Kultur auf Gingkoeier- nährboden und
c. avirulente Kochsche Bazillen
1 Woche alte Kultur auf Gingkoeier- nährboden;

4. Tuberkulöses Sputum:
a. Bazillen massenhaft und Granula negativ,
b. Bazillen spärlich und Granula mässig und
c. Bazillen negativ und Granula spärlich;

5. Pleuraexsudat und

6. Avirulente Koch sche Bazillen.

1, 3, 5, 15 Tage und 1-6 Monate lang kultivierte Bazillen.

Kontrolle :

1. Filtrat, bei $60^{\circ} \mathrm{C} 1$ Stunde lang erhitzt,

2. Alt-Tuberkulin,

3. Albumosefreies Tuberkulin,

4. Alt-Tuberkulin + Schweineserum,

5. Albumosefreies Tuberkulin + Schweineserum und

6. Organemulsion normaler Meerschweinchen und Filtrat aus dieser Emulsion.

Die auf festem Nährboden kultivierten Bazillen wurden mitPlatinöse entnommen, gewogen, im Achatmörser genügend verrieben und unter tropfenweise zugesetzter physiologischer Kochsalzlösung emulgiert. (Kochsalzlösung $5 \mathrm{ccm}$ gegen $2 \mathrm{mg}$ Bazillen). Die Kultur auf flïssigem Nährboden wurde genügend geschüttelt, der grössere Teil der Bazillenmasse daraus entfernt und direkt filtriert. Um Bazillen im Wachstumsbeginn zu gewinnen, kultivierte ich sie 1-3 und 5-10 Tage lang auf festem Nährboden; bevor sich makroskopisch irgendein Wachstum zeigte, goss ich je $5 \mathrm{ccm}$ physiologischer Kochsalzlösung in jeden Nährboden. Dabei rieb ich die Nährbodenoberfläche leise und gewann so eine leicht diffus getrübte Flüssigkeit, die dann als filtrierbares Material benutzt wurde.

Das Sputum nahm ich in ein Glas auf und liess es 2 Tage lang, das Glas mit Wattepfropf fest verschlossen, bei $37^{\circ} \mathrm{C}$ im Brutschrank stehen, wobei sich Autolyse entwickelte. Dann verdünnte ich es mit physiologischer Kochsalzlösung ums 10fache und filtrierte es vor dem Gebrauch noch einmal mit sterilem Papierfilter. 
Das Pleuraexsudat liess ich 5 Tage lang bei $37^{\circ} \mathrm{C}$ stehen, verdünnte es dann ums 2 fache und liess es einmal durch steriles Papierfilter hindurehgehen.

\section{Filtriermethode.}

Benutzt wird ein durchaus steriler verzweigter Kolben, mit dem ein durch trockene Hitze sterilisierter Chamberland L3 mit Gummipfropfen gut verbunden wird sowie einer der Kolbenzweige durch einen Gummischlauch mit Wasserpumpe und Manometer. Filtriert wurde unter einem negativen Druck von $15-30 \mathrm{~cm} \mathrm{Hg}$ und zwar 10 Minuten bis 3 Stunden lang.

\section{Untersuchung des Filtrats und Tierexperiment.}

Das so gewonnene Filtrat entnahm ich jedesmal mit steriler Pipette und kultivierte einen Teil davon sogleich auf Agar, Gingkoeiernährboden, Hohnschem u. Löwensteinschem Nährboden. Den anderen Teil zentrifugierte ich 20 Minuten lang mit 3000 Rotationen pro Minute; der dabei entstehende Bodensatz wurde nach Zi ehlNeelsenscher und Much-We issscher Methode gefärbt und mikroskopisch untersucht. Vom Rest impfte ich je $2-5 \mathrm{ccm}$ auf Tiere, hauptsächlich subkutan am rechten Oberschenkel, selten intraperitoneal.

\section{Beobachtung der Versuchstiere.}

Die Versuchstiere wurden 1 Woche vor der Impfung jedes für sich isoliert gehalten. Ich benutzte diejenigen, deren Tuberkulinreaktion $(0,1 \mathrm{ccm}$ Alt-Tuberkulin in 5facher Verdünnung, intrakutan) sich als negativ erwies. Das Körpergewicht wurde jede Woche gemessen. Die Tiere sezierte ich unmittelbar nach dem Tode, zum Teil auch, nachdem die Tiere durch Einfïhrung von Luft in ihr Herz getötet worden waren.

Bei der. Sektion mass ich stets die Grösse aller Lymphdrüsen und der Milz, ferner nahm ich Leber und Lunge heraus und prüfte, ob sie sich makroskopisch verändert hatten. Dann nahm ich je ein Stückchen dieser Organe, brachte es auf ein Objektglas, färbte die Strichpräparate und untersuchte es auf Bazillen oder Granula. Die anderen Teile der Organe warf ich in einen sterilen Mörser, zerrieb sie tüchtig und bereitete mit 3-5\% iger Schwefelsäure eine Emulsion. Diese Emulsion liess ich 30 Minuten lang stehen und zentrifugierte sie dann 20 Minuten lang mit 3000 Rotationen pio Minute. Den dadurch entstelienden Bodensatz züchtete ich sogleich auf Gingkoeier-, Hohn- 
schem und Löwensteinschem Nährboden. Ich konservierte den Rest zur histologischen Untersuchung in 10\%igem Formalin.

\section{Versuchsergebnisse.}

A. Junge Kulturbazillen.

\section{Versuch 1.}

Material: 1 Monat lang auf Hohnschem Nährboden kultivierter Typus

Tabelle

Versuch mit dem Filtrat aus

\begin{tabular}{|c|c|c|c|c|c|c|c|c|c|c|}
\hline \multirow[b]{2}{*}{$\begin{array}{c}\text { Filtrations- } \\
\text { material }\end{array}$} & \multirow[b]{2}{*}{ 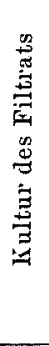 } & \multirow{2}{*}{ 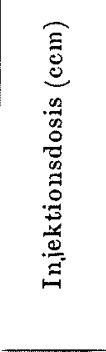 } & \multirow[b]{2}{*}{ 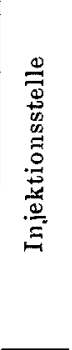 } & \multirow{2}{*}{ 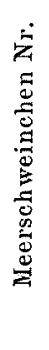 } & \multirow[b]{2}{*}{ 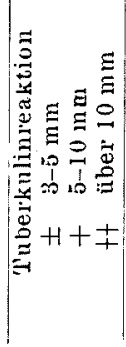 } & \multirow[b]{2}{*}{ 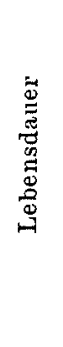 } & \multirow[b]{2}{*}{ 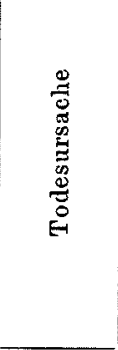 } & \multicolumn{3}{|c|}{ Körpergewicht } \\
\hline & & & & & & & & 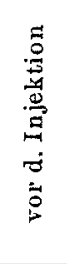 & 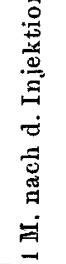 & 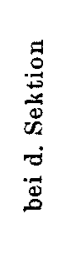 \\
\hline \multirow{6}{*}{$\begin{array}{c}\text { Ty) } \\
\text { Typus } \\
\text { humanus } \\
(1 \text { Monat alt })\end{array}$} & \multirow{6}{*}{-} & & \multirow{9}{*}{ s.e. \{} & 1 & - & 118 & Gestorb. & 310 & 330 & 320 \\
\hline & & 5 & & 2 & - & 120 & $"$ & 270 & 310 & 280 \\
\hline & & & & 3 & - & 10 & $"$ & 290 & & 270 \\
\hline & & & & 4 & - & 120 & $"$ & 305 & 330 & 355 \\
\hline & & $2 \times 2 \times 2$ & & 5 & $(2-7 \mathrm{~W})$. & 56 & $"$ & 300 & 340 & 300 \\
\hline & & & & 6 & - & 7 & $"$ & 280 & & 220 \\
\hline Kontrolle & & \multirow{3}{*}{5} & & & & & & & & \\
\hline \multirow{2}{*}{$\begin{array}{l}\text { Erhitztes } \\
\text { Filtrat }\end{array}$} & & & & 7 & - & 65 & $"$ & 280 & 330 & 380 \\
\hline & & & & 8 & -- & 110 & $"$ & 310 & 350 & 360 \\
\hline \multirow{3}{*}{$\begin{array}{c}\text { Ty) } \\
\text { bovinus } \\
\text { (1 Monat alt) }\end{array}$} & \multirow{3}{*}{ - } & \multirow{3}{*}{2} & \multirow{6}{*}{ i.p. \{} & 45 & $(3 \stackrel{ \pm}{W})$. & 118 & Gestorb. & 360 & 320 & 300 \\
\hline & & & & 46 & $(1-3 \mathrm{~W})$. & 60 & Getötet & 400 & 390 & 350 \\
\hline & & & & 47 & ( $1 \mathrm{~W})$. & 20 & $"$ & 380 & & 410 \\
\hline Kontrolle & & \multirow{3}{*}{2} & & & & & & & & \\
\hline \multirow{2}{*}{$\begin{array}{l}\text { Erhitztes } \\
\text { Filtrat }\end{array}$} & & & & 48 & $(1 \stackrel{ \pm}{W})$. & 69 & Gestorb. & 350 & 340 & 320 \\
\hline & & & & 49 & $\left|\left(1-\frac{ \pm}{7} \mathrm{~W}.\right)\right|$ & 111 & " & 400 & 360 & 270 \\
\hline
\end{tabular}


humanus; Verhältnis der Emulsion: $2 \mathrm{mg}$ Bazillen zu $5 \mathrm{ccm}$ physiologischer Kocbsalzlösung; Kontrolle der Filtration: bazillus prodigiosus; Filtration: durch Chamberland L3, negativer Druck $15 \mathrm{~cm} \mathrm{Hg}$, Filtrierdauer 15 Minuten. Die mikroskopische und kulturelle Untersuchung des Filtrats endete negativ.

Das Filtrat wurde auf 6 Tiere geimpft und überdies zur Kontrolle ein bei $60^{\circ} \mathrm{C} 1$ Stunde lang erhitztes Filtrat auf 2 andere Tiere. Dabei gewann ich die in Tabelle I (a) wiedergegebenen Ergebnisse.

Wie man aus der Tabelle ersieht, ist die Tuberkulinreaktion bei einem (Nr.5) der Tiere, denen 3 mal nacheinander mit 2 Tagen Inter-

I $(a, b)$.

junger Tuberkelbazillenkultur.

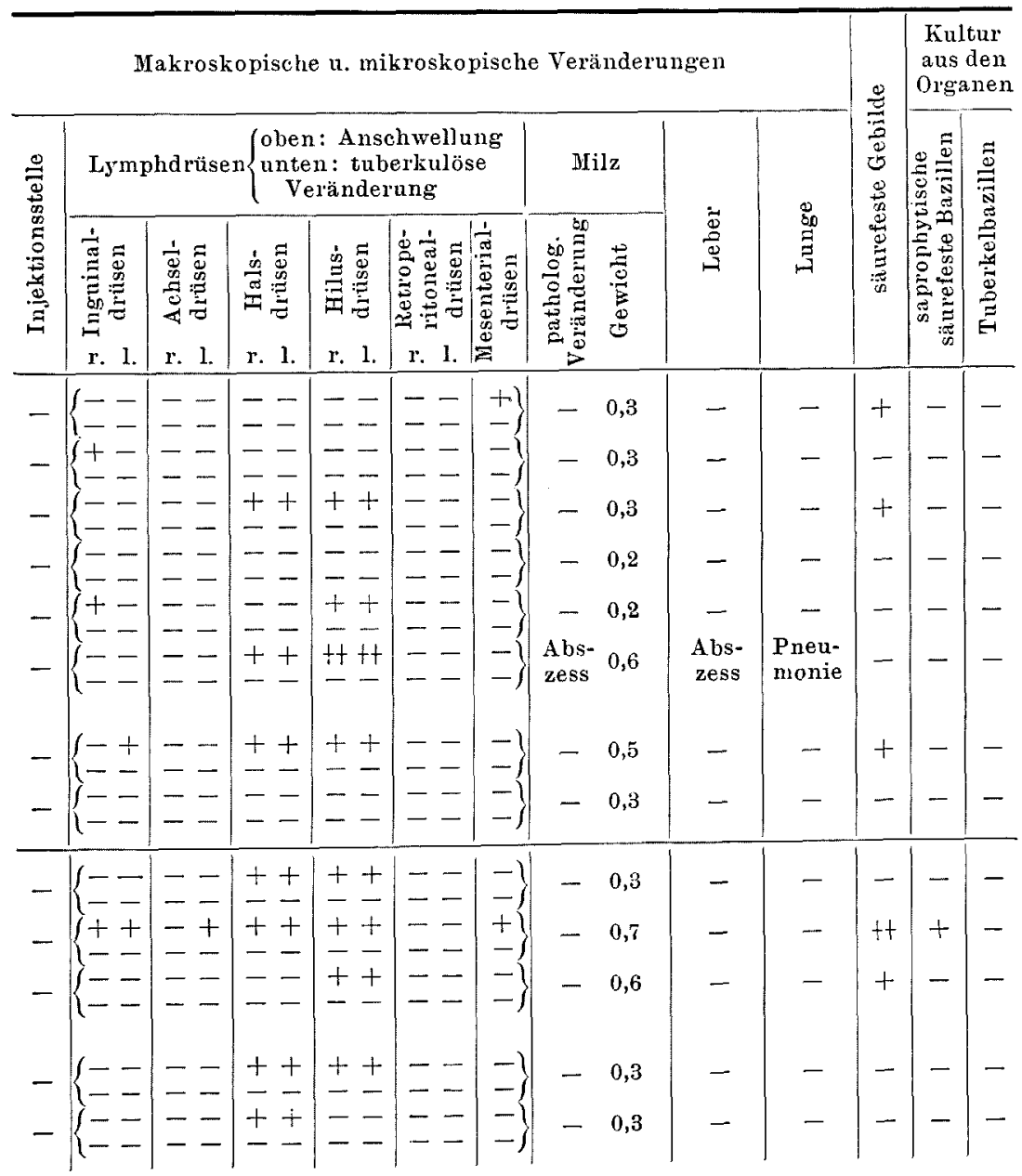


vall jedesmal $2 \mathrm{ccm}$ Filtrat eingeimpft worden war, 2-7 Wochen lang positiv, sonst sind alle negativ. Das Körpergewicht nimmt nach 1 Monat sowohl bei den mit Filtrat als auch bei den mit erhitztem Filtrat geimpften Tieren zu. Bei der Sektion bemerkt man makroskopisch wie mikroskopisch keine tuberkulösen Veränderungen an den Organen. Nur an 2 der mit Filtrat und 1 der mit erhitztem Filtrat geimpften Tiere fand man säurefeste Gebilde. Die Kulturen aus den Organen dieser Tiere erwiesen sich alle als negativ.

\section{Versuch 2.}

Material: 1 Monat lang auf Gingkoeiernährboden kultivierter Typus bovinus; Verhältnis der Emulsion: wie beim Versuch 1; Kontrolle der Filtration: bazillus prodigiosus; Filtration : durch Chamberland L3, negativer Druck $15 \mathrm{~cm}$ $\mathrm{Hg}$, Dauer 10 Minuten.

Das Ergebnis der mikroskopischen und kulturellen Untersuchung war negativ.

Das Filtrat wurde auf 3 Tiere, das erhitzte Filtrat auf 2 geimpft. Das Ergebnis gibt Tabelle I (b) wieder. Wie aus dieser Tabelle zu ersehen, ist die Tuberkulinreaktion sowohl bei den mit Filtrat als auch bei den mit erhitztem Filtrat geimpften Tieren schwach positiv. Bei beiden hat das Körpergewicht abgenommen. Die tuberkulösen Veränderungen der Organe sind bei beiden Gruppen negativ. Bei zweien der 3 mit Filtrat geimpften Tiere wurden säurefeste Gebilde wahrgenommen. Vom Tier Nr. 46 konnte man eine Reinkultur einer Art säurefester Bazillen erhalten. Diese Kultur entwickelte sich nach 1 Monat gold-gelb, feucht und maulbeerartig, wenn man die Organe mit $5 \%$ iger Schwelsäure behandelte. Bei näherer Untersuchung fand man, dass die Stäbchen an beiden Enden spitzig und 1-6 $\mu$ lang sind. Sie zeigen sich bei $Z$ iehl-Neels en scher Färbung als solide oder als segmentierte Stäbchen. Hier und da findet man an diesen Stäbchen granulaförmige und bläulich gefärbte Teile. Bei $\mathrm{Much}-\mathrm{W}$ eis sscher Doppelfärbung sind 1-5 Granula zu sehen. Obige Kultur entwickelt sich bei weiterer Kultivierung auf Gingkoeier-, Löw enstein schem Nährboden oder Glyzerinagar ungefähr nach 5 Tagen und wächst allmählich zu einem feuchten und amorphen Bazillenbelag an. Sie ist auf einfachem Agar und 1\% igem Mannitagar nicht züchtbar. Wenn sie auf Tiere geimpft wird, so zeigt das Tier nach 1 Monat auf AltTuberkulin keine Reaktion. Bei der Sektion bemerkt man an den Organen keine spezifischen Veränderungew. Daraus sieht man, dass diese Bazillen keine Tuberkelbazillen sind, sondern nichtpathogene, säurefeste Stäbchen anderer Art sein müssen.

Die zwei eben beschriebenen Versuche bieten keinen positiven Beweis für die Filtrierbarkeit des Tuberkelbazillus. 


\section{B. Alte Kulturbazillen.}

Versuch 3.

Material: 2 Monate lang auf Lockemannschem Nährboden kultivierte Bazillen des Typus humanus; man schüttelt diese Kultur genügend, fügt ihr bac. prodigiosus hinzu und filtriert sie durch Chamberland L3, unter einem negativen Druck ron $20 \mathrm{~cm} \mathrm{Hg}$; Filtrationsdauer 20 Minuten. Mikroskopische und kulturelle Untersuchung des Filtrats zeigte negative Ergebnisse. Das Ergebnis der Impfung des Filtrats auf 5 Meerschweinchen und des erhitzten Filtrats auf 2 Tiere gibt Tabelle II (a) übersichtlich wieder.

Diese Tabelle zeigt, dass die Tuberkulinreaktion bei 2 der 5 mit Filtrat geimpften Tiere positiv (Nr. 23, 25) ausfiel. Bei Nr. 23 war sie 1-8 Wochen, bei Nr. 25 nur 1 Woche lang schwach positiv. Die mit erhitztem Filtrat geimpften Tiere zeigen alle negative Reaktion. Das Körpergewicht nahm bei beiden Gruppen ab. Bei der Sektion nahm man Lymphdrüsenschwellung wahr, aber ohne Unterschied zwischen Versuchs- und Kontrolltieren. Bei 2 mit Filtrat geimpften Tieren zeigten sich säurefeste Gebilde, deren Kultur aber negativ ausfiel.

\section{Versuch 4.}

Material: 4 Monate lang auf Gingkoeiernährboden kultivierter Typus humanus; Verhältnis der Emulsion: ebenso wie im 1. Versuch; Filtration: durch Chamberland L3, negativer Druck von $20 \mathrm{~cm} \mathrm{Hg}$, Dauer 15 Minuten; Filtrationskontrolle: bacillus prodigiosus. Mikroskopische und kulturelle Untersuchung des Filtrats fiel negativ aus.

Die Impfung des Filtrats auf 2 Tiere und die des erhitzten Filtrats auf 1 Tier ergaben, was Tabelle II (b) zeigt. Alle Tiere starben an Pneumonie. Tuberkulinreaktion bei allen negativ. Körpergewichtsabnahme. Bei 1 der mit Filtrat geimpften Tiere fand man säurefeste Gebilde, deren Kultur aber negativ endete.

\section{Versuch 5 .}

Material: 1 Jahr lang auf Hohnschem Nührboden kultivierter Typus humanus. Man bereitete eine Bazillenemulsion, fügte bacillus prodigiosus hinzu und filtrierte sie durch Chamberland L3 unter negativem Druck von $15 \mathrm{~cm}$ $\mathrm{Hg}$, Filtrationsdauer 30 Minuten.

Sowohl bei mikroskopischer als auch kultureller Untersuchung negativ Ergebnisse. Impfung des Filtrats auf 3 Tiere und die des erhitzten Filtrats auf 1 Tier. Die Ergebnisse zeigt Tabelle II (c). Danach nimmt das Körpergewicht sowohl bei den mit Filtrat wie bei den mit erhitztem Filtrat geimpften Tieren zu. Die Tuberkulinreaktion war bei 2 der mit Filtrat geimpften Tiere nach 3 Wochen schwach positiv und ebenso auch bei den mit erhitztem Filtrat geimpf- 
Tabelle II

Versuch mit dem Filtrat aus

\begin{tabular}{|c|c|c|c|c|c|c|c|c|c|c|}
\hline \multirow[b]{2}{*}{$\begin{array}{l}\text { Filtrations- } \\
\text { material }\end{array}$} & \multirow{2}{*}{ 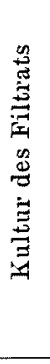 } & \multirow{2}{*}{ 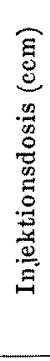 } & \multirow[b]{2}{*}{ 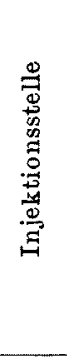 } & \multirow{2}{*}{ 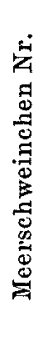 } & \multirow{2}{*}{ 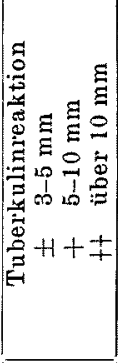 } & \multirow[b]{2}{*}{ 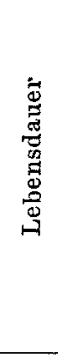 } & \multirow[b]{2}{*}{ 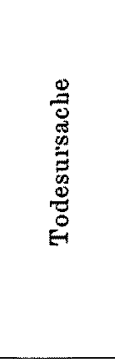 } & \multicolumn{3}{|c|}{ Körpergewicht } \\
\hline & & & & & & & & 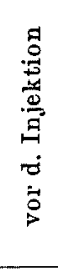 & 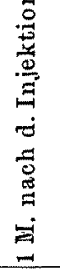 & 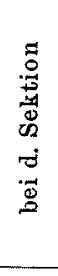 \\
\hline \multirow{5}{*}{$\begin{array}{c}\text { (a) } \\
\text { Typus } \\
\text { humanus } \\
(2 \mathrm{M} . \text { alt })\end{array}$} & \multirow{5}{*}{-} & \multirow{3}{*}{3} & \multirow{3}{*}{ s.c. } & 23 & $\left(1-8^{+} \mathrm{W}\right)$ & 109 & Gestorb. & 590 & 575 & 490 \\
\hline & & & & 24 & - & 25 & $"$ & 500 & & 500 \\
\hline & & & & 25 & $(\stackrel{ \pm}{W})$. & 20 & $"$ & 590 & & 455 \\
\hline & & \multirow{2}{*}{5} & \multirow{2}{*}{ i.p. } & 26 & - & 67 & $"$ & 510 & 455 & 410 \\
\hline & & & & 27 & - & 53 & $"$ & 450 & 390 & 350 \\
\hline \multicolumn{11}{|l|}{ Kontrolle } \\
\hline \multirow{2}{*}{$\begin{array}{c}\text { Erhitztes } \\
\text { Filtrat }\end{array}$} & & \multirow[t]{2}{*}{3} & \multirow{2}{*}{$\begin{array}{l}\text { s.c. } \\
\text { i.p. }\end{array}$} & \multirow{2}{*}{$\begin{array}{l}28 \\
29\end{array}$} & \multirow{2}{*}{-} & \multirow{2}{*}{$\begin{array}{l}119 \\
154\end{array}$} & \multirow[t]{2}{*}{$"$} & \multirow{2}{*}{$\begin{array}{l}430 \\
430\end{array}$} & 400 & \multirow{2}{*}{$\begin{array}{l}310 \\
330\end{array}$} \\
\hline & & & & & & & & & 400 & \\
\hline \multirow{2}{*}{$\begin{array}{c}\text { (b) } \\
\text { Typus } \\
\text { humanus } \\
\text { (4 M. alt) }\end{array}$} & \multirow{2}{*}{-} & \multirow{2}{*}{2} & \multirow{4}{*}{ s.c. } & \multirow{3}{*}{$\begin{array}{r}74 \\
75\end{array}$} & \multirow{3}{*}{-} & \multirow{3}{*}{$\begin{array}{l}23 \\
18\end{array}$} & \multirow{3}{*}{$\begin{array}{c}\text { Gestorb. } \\
"\end{array}$} & 420 & & 320 \\
\hline & & & & & & & & 410 & & 360 \\
\hline Kontrolle & & & & & & & & & & \\
\hline $\begin{array}{l}\text { Erhitztes } \\
\text { Filtrat }\end{array}$ & & 2 & & 76 & - & 17 & $"$ & 500 & & 450 \\
\hline (c) & & & & 9 & $\stackrel{ \pm}{ \pm}$ & 97 & Gestorb. & 340 & 340 & 290 \\
\hline $\begin{array}{c}\text { Typus } \\
\text { humanus }\end{array}$ & & & s.c. & 10 & $(3 \stackrel{ \pm}{W})$ & 193 & $"$ & 320 & 355 & 400 \\
\hline ( $1 \mathrm{Jahr}$ & - & 5 & & 11 & & 15 & $"$ & 320 & & 240 \\
\hline Kontrolle & & & & & & & & & & \\
\hline $\begin{array}{c}\text { Erhitztes } \\
\text { Filtrat }\end{array}$ & & & s.c. & 12 & $(3 \stackrel{ \pm}{w})$. & 193 & $"$ & 290 & 300 & 280 \\
\hline
\end{tabular}

ten Tieren. Tuberkulöse Veränderungen der Organe waren nicht zu finden, auch keine säurefesten Gebilde, und die Kultur fiel ebenfalls negativ aus. Durch obigen Versuch ist festgestellt worden, dass auch das Filtrat lange kultivierter Bazillen keine Veränderungen bei Tieren hervorbringt. 
$(a, b, c)$.

alter Tuberkelbazillenkultur.

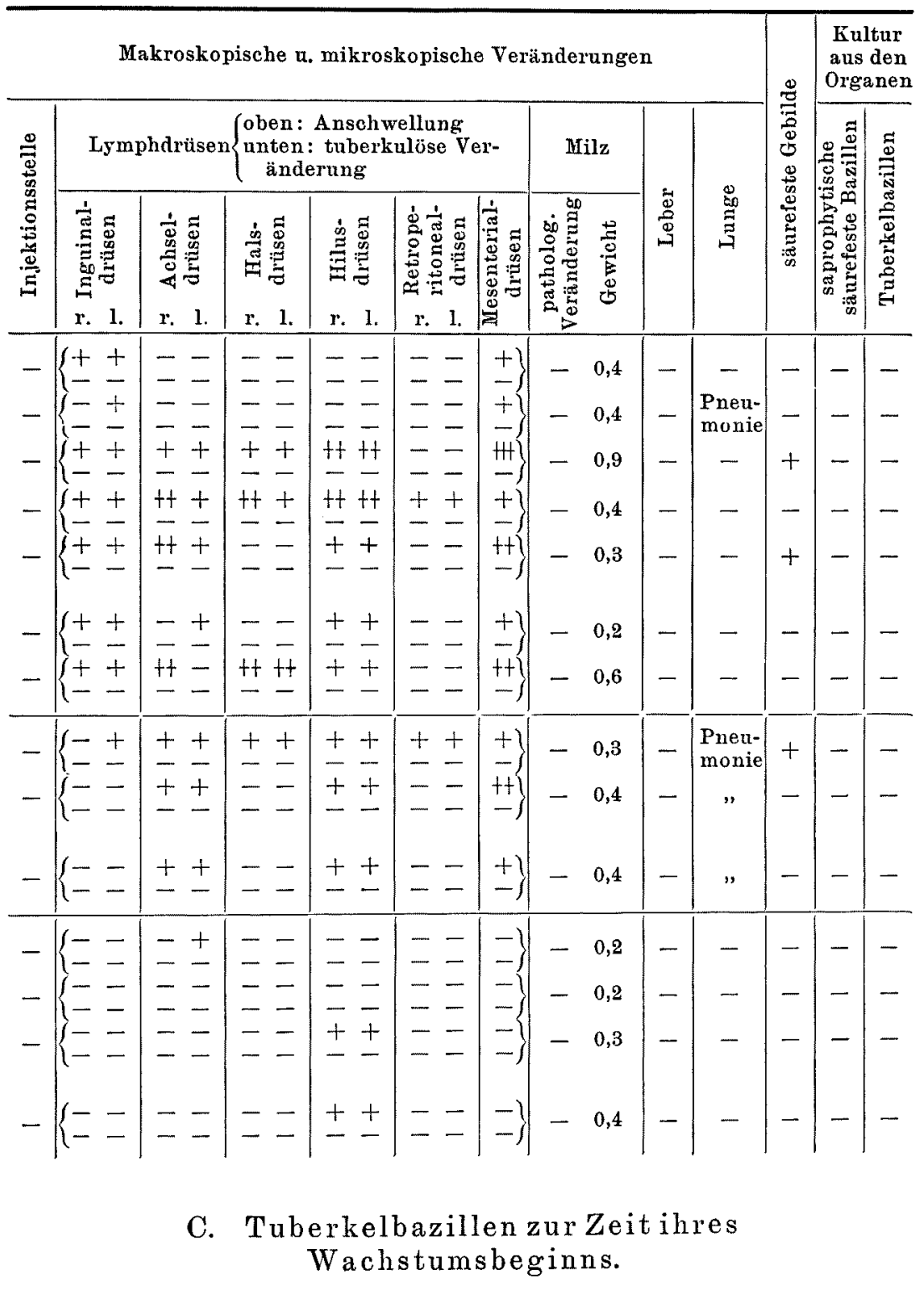

Bei obigen 5 Versuchen konnte ich kein filtrierbares Tuberkulosevirus finden. Durch die Mitteilung von $\mathrm{Kahn}^{57)}$ (1929) über das An- 
fangswachstum der Tuberkelbazillen wurde ich auf die Vermutung geführt, dass es möglicherweise zur Zeit des Wachstumsbeginns filtrierbar wäre. Deshalb führte ich noch weitere Versuche aus.

\section{Versuch 6.}

Material: 1-3 Tage lang auf Gingkoeiernährboden kultivierter Typus humanus.

Man züchtete den Typus humanus auf Gingkoeiernährboden und erhielt daraus je eine 1-, 2- und 3tägige Kultur; in die makroskopisch noch kein Wachstum zeigende Kulturen goss ich physiologische Kochsalzlösung, rieb die

Tabelle III

Versuch mit dem Filtrat aus der Tuberkelbazillen

\begin{tabular}{|c|c|c|c|c|c|c|c|c|c|c|}
\hline \multirow[b]{2}{*}{$\begin{array}{c}\text { Filtrations- } \\
\text { material }\end{array}$} & \multirow{2}{*}{ 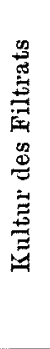 } & \multirow{2}{*}{ 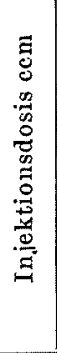 } & \multirow{2}{*}{ 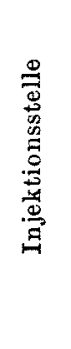 } & \multirow{2}{*}{ 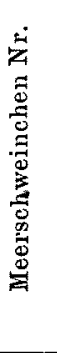 } & \multirow{2}{*}{ 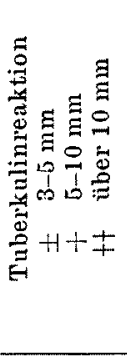 } & \multirow[b]{2}{*}{ 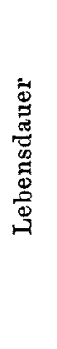 } & \multirow[b]{2}{*}{ 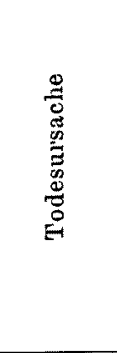 } & \multicolumn{3}{|c|}{ Körpergewicht } \\
\hline & & & & & & & & 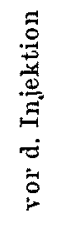 & 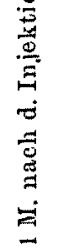 & 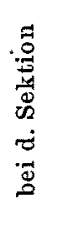 \\
\hline $\begin{array}{c}\text { (a) } \\
\text { Typus } \\
\text { humanus } \\
(1-3 \text { Tage alt })\end{array}$ & - & 2 & s.c. & $\begin{array}{l}39 \\
41 \\
42 \\
43\end{array}$ & $\begin{array}{c} \pm \\
(2-4 W .) \\
\pm \\
(2-6 W .) \\
+ \\
(2-4 W .) \\
(2-6 W .)\end{array}$ & $\begin{array}{l}76 \\
60 \\
38 \\
94\end{array}$ & $\begin{array}{c}\text { Gestorb. } \\
\quad " \\
" \\
"\end{array}$ & $\begin{array}{r}550 \\
-590 \\
580 \\
550\end{array}$ & $\begin{array}{l}410 \\
370 \\
410 \\
380\end{array}$ & $\begin{array}{l}400 \\
350 \\
410 \\
320\end{array}$ \\
\hline $\begin{array}{c}\text { (b) } \\
\text { wie a) }\end{array}$ & - & 2 & s.c. \{ & $\begin{array}{l}70 \\
71\end{array}$ & $\begin{array}{c}(2 \stackrel{ \pm}{W} .) \\
\pm \\
(1 \stackrel{+}{W} .) \\
\pm \\
\left(1 \frac{w}{W} .\right)\end{array}$ & $\begin{array}{l}40 \\
24 \\
30\end{array}$ & $\begin{array}{c}\text { Gestorb. } \\
" \\
"\end{array}$ & $\begin{array}{l}260 \\
270 \\
260\end{array}$ & $\begin{array}{l}280 \\
260\end{array}$ & $\begin{array}{l}260 \\
250 \\
260\end{array}$ \\
\hline $\begin{array}{c}\text { Kontrolle } \\
\text { Erhitztes } \\
\text { Filtrat }\end{array}$ & & & i.p. \{ & $\begin{array}{l}72 \\
73\end{array}$ & & 9 & $"$ & 240 & & 210 \\
\hline $\begin{array}{c}(\mathbf{c}) \\
\text { wie a) }\end{array}$ & 7 & 9 & & $\begin{array}{l}77 \\
78\end{array}$ & $\begin{array}{c}\stackrel{ \pm}{ \pm} \\
(1-3 \mathrm{~W} .) \\
-\end{array}$ & $\begin{array}{l}27 \\
27\end{array}$ & $\begin{array}{c}\text { Gestorb. } \\
"\end{array}$ & $\begin{array}{l}500 \\
400\end{array}$ & & $\begin{array}{l}330 \\
250\end{array}$ \\
\hline $\begin{array}{c}\text { Kontrolle } \\
\text { Erhitztes } \\
\text { Filtrat }\end{array}$ & & & & 79 & $\left(1^{ \pm} \mathrm{W}.\right)$ & 18 & $"$ & 440 & & 350 \\
\hline
\end{tabular}


Năhrbodenoberfläche leise mit der Platinöse und liess die Bazillen in die Kochsalzlösung eindringen. Diese filtrierte ich durch ein Papierfilter, fügte bacillus prodigiosus hinzu und filtrierte es durch Chamberland L3. Negativer Druck: $20 \mathrm{~cm} \mathrm{Hg}$. Filtrationsdauer: 30 Minuten.

Solches Filtrat bereitete ich bei 3 Stämmen ( $a, b, c)$ des Typus humanus. Die mikroskopische und kulturelle Untersuchung des Filtrats endete negativ. Das Filtrat (a) spitzte ich 4 Meerschweinchen ein, das Filtrat (b) 3 und das erhitzte Filtrat (b) 1 Tier, das Filtrat (c) 2 und das erhitzte Filtrat (c) 1 Tier.

Das Ergebnis gibt Tabelle III ( $a, b, c)$ wieder.

a) Die Tuberkulinreaktion war bei allen schwach positiv und wurde nach 6 Wochen negativ. Das Körpergewicht nahm bei allen

$$
(a, b, c, d, e) \text {. }
$$

kultur zur Zeit ihres Wachstumsbeginns.

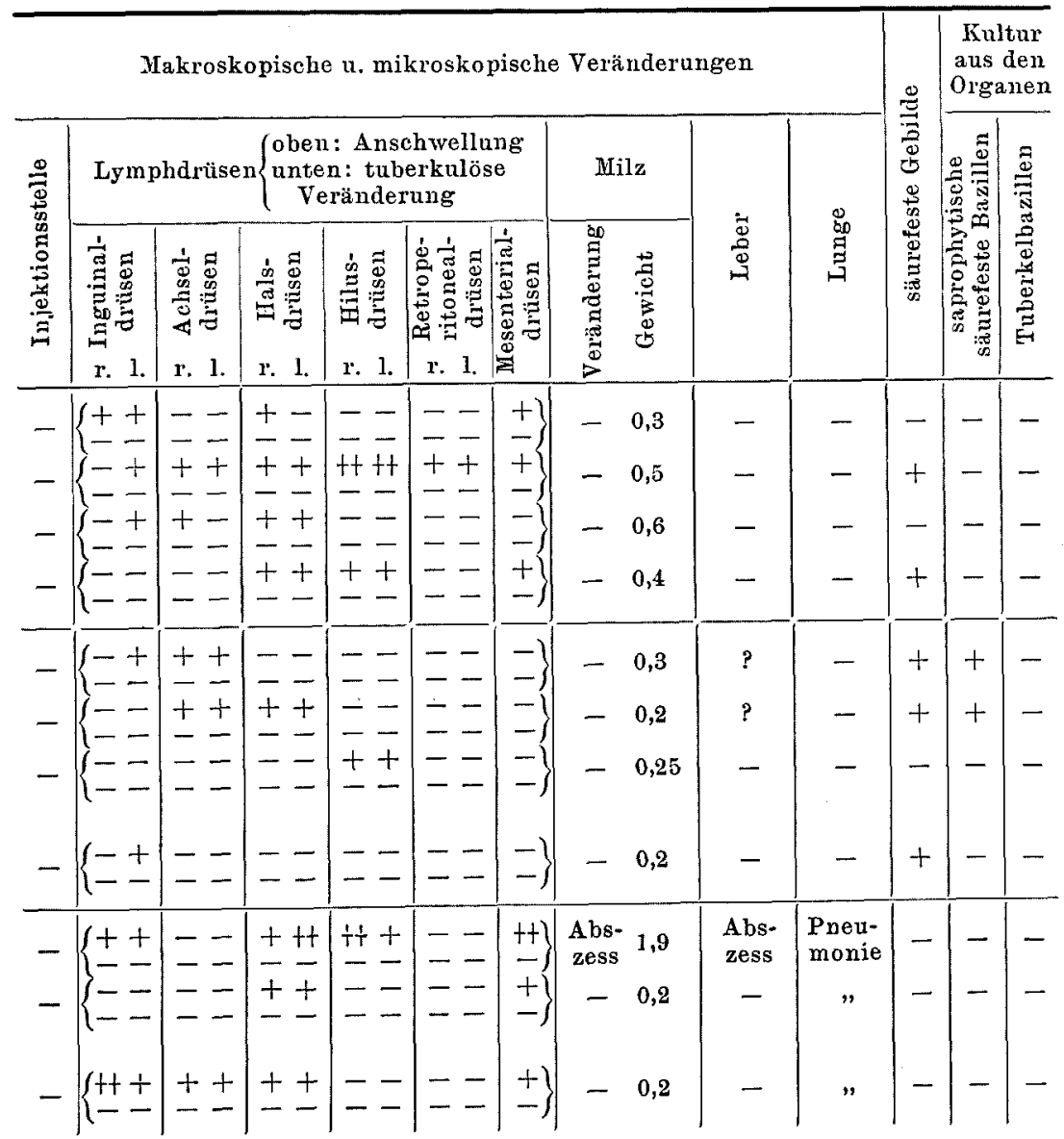




\begin{tabular}{|c|c|c|c|c|c|c|c|c|c|c|}
\hline \multirow[b]{2}{*}{$\begin{array}{l}\text { Filtrations- } \\
\text { material }\end{array}$} & \multirow{2}{*}{ 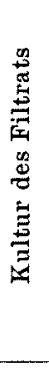 } & \multirow{2}{*}{ 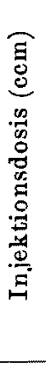 } & \multirow[b]{2}{*}{ 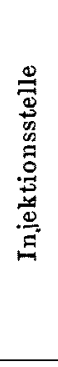 } & \multirow{2}{*}{ 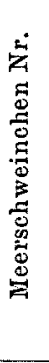 } & \multirow{2}{*}{ 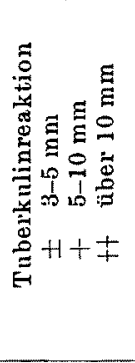 } & \multirow[b]{2}{*}{ 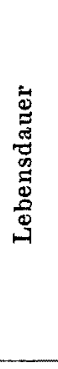 } & \multirow[b]{2}{*}{ 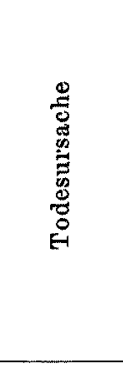 } & \multicolumn{3}{|c|}{ Körpergewicht } \\
\hline & & & & & & & & 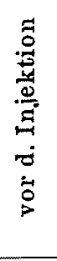 & 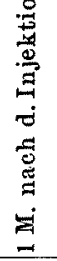 & 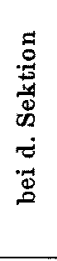 \\
\hline $\begin{array}{c}(\mathbf{d}) \\
\text { Typus } \\
\text { humanus } \\
(5-10 \text { Tage alt }) \\
\end{array}$ & \multirow[t]{2}{*}{-} & \multirow[t]{2}{*}{2} & \multirow{2}{*}{ s.c. } & $\begin{array}{l}80 \\
81\end{array}$ & - & $\begin{array}{l}30 \\
30\end{array}$ & $\begin{array}{c}\text { Getötet } \\
\qquad "\end{array}$ & $\begin{array}{l}480 \\
470\end{array}$ & & $\begin{array}{r}410 \\
450\end{array}$ \\
\hline $\begin{array}{c}\text { Kontrolle } \\
\text { Eiritztes } \\
\text { Filtrat }\end{array}$ & & & & 82 & - & 30 & $"$ & 460 & & 460 \\
\hline $\begin{array}{c}\text { (e) } \\
\text { avirulente } \\
\text { Kochsche } \\
\text { Bazillen } \\
\text { (1 W. alt) }\end{array}$ & \multirow[t]{2}{*}{ - } & \multirow[t]{2}{*}{2} & \multirow[t]{2}{*}{ s.e. } & $\begin{array}{l}50 \\
51 \\
52\end{array}$ & $\begin{array}{c}\stackrel{ \pm}{ \pm}(2-6 \mathrm{~W}) \\
- \\
-\end{array}$ & $\begin{array}{r}100 \\
101 \\
34\end{array}$ & $\begin{array}{c}\text { Getötet } \\
\text { Gestorb. } \\
\quad "\end{array}$ & $\begin{array}{l}420 \\
270 \\
310\end{array}$ & $\begin{array}{l}440 \\
310 \\
300\end{array}$ & $\begin{array}{l}460 \\
320 \\
280\end{array}$ \\
\hline $\begin{array}{c}\text { Kontrolle } \\
\text { Erhilztes } \\
\text { Filtrat }\end{array}$ & & & & 53 & - & 10 & $"$ & 280 & & 260 \\
\hline
\end{tabular}

ab. Keine tuberkulöse Veränderungen an den Organen. Aber bei 2 unter den 4 Tieren waren säurefeste Gebilde bemerkbar.

b) Die Tuberkulinreaktion war bei den mit Filtrat (b) geimpften Tieren 1-2 Wochen lang ganz schwach positiv, aber bei den mit erhitztem Filtrat geimpften negativ. Körpergewichtsabnahme bei allen. Bei Nr. 70 und 71 fand man geringe Anschwellung der Lymphdrüsen, aber keine sonstigen auffallenden Veränderungen. Nichts Besonderes an Milz und Lungen zu sehen. An der Leber fand man ein miliargrosses Knötchen, in dem man bei der Färbung säurefeste Gebilde bemerkte. Aus Gebilden bereitete ich mit 5\% iger Schwefelsäure eine Organemulsion. Diese Emulsion züchtete ich auf Gingkoeiernährboden und fand nach 14 Tagen bei $\mathrm{Nr} .70$ ganz die gleichen gelblichen, feuchten, maulbeerartigen Kolonien wie bei Nr. 46. Durch.weitere Kultur und Tierversuche sah ich, dass $\mathrm{Nr}$. 70 sich ganz gleich wie $\mathrm{Nr}$. 46 verhält. Bei Nr. 71 fand ich nach 1 Monat viele weisse, miliargrosse Kolonien. Äusserlich sehen sie ganz wie Tuberkelbazillen aus. Aber weitere Kulturen wachsen auf Agar, Glyzerinagar und anderen Tuberkelbazillennährböden schnell und bilden nach 2-3Tagen 


\begin{tabular}{|c|c|c|c|c|c|c|c|c|c|c|c|c|c|}
\hline & & $\operatorname{canz} 0$ & c) & e $u . n$ & ko & $p$ & Ver: & & & & & $\begin{array}{l}\text { Ku } \\
\text { aus } \\
\text { Orge }\end{array}$ & $\begin{array}{l}\text { ltur } \\
\text { den } \\
\text { anen }\end{array}$ \\
\hline$\stackrel{0}{\stackrel{0}{0}}$ & Lym & phdrüs & $n\left\{\begin{array}{c}\text { obe } \\
\text { unt } \\
V\end{array}\right.$ & ane & $\begin{array}{l}\text { rkulö } \\
\text { ing }\end{array}$ & & $M$ & ilz & & & $\begin{array}{l}3 \\
0 \\
0 \\
0 \\
0\end{array}$ & 竞 & $\stackrel{a}{0}$ \\
\hline 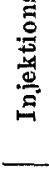 & 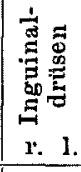 & 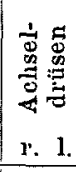 & 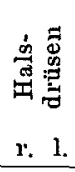 & 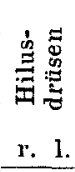 & 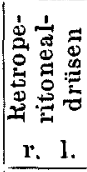 & 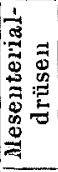 & 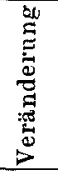 & 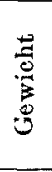 & 兽 & 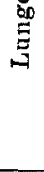 & & 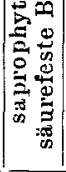 & 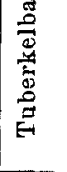 \\
\hline- & $\left\{\begin{array}{l}-- \\
-=\end{array}\right.$ & -- & $=-$ & \pm+ & $=$ & $\begin{array}{l}-1 \\
-\end{array}$ & & 0,2 & - & - & - & - & - \\
\hline- & $\left\{\begin{array}{l}1-= \\
-\end{array}\right.$ & $=-$ & $=$ & \pm & -- & $-\}$ & & 0,2 & - & - & - & - & \\
\hline - & $\left\{\begin{array}{l}-- \\
--\end{array}\right.$ & $\overline{-}$ & \pm+ & \pm \pm & $=$ & 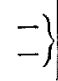 & & 0,2 & - & - & - & - & - \\
\hline - & $\left\{\begin{array}{l}-- \\
--\end{array}\right.$ & $\begin{array}{l}-- \\
--\end{array}$ & \pm & $=-$ & $\overline{-}$ & \pm & & 0,5 & - & & - & - & - \\
\hline- & $\left\{\begin{array}{l}+- \\
--\end{array}\right.$ & \pm+ & \pm+ & \pm+ & $=-$ & $\begin{array}{l}-y \\
-7\end{array}$ & & 0,2 & - & - & - & - & - \\
\hline- & $\left\{\begin{array}{l}-= \\
--\end{array}\right.$ & $\pm=$ & $=$ & $\pm=$ & $=-$ & -3 & & 0,3 & - & - & - & - & - \\
\hline - & $\left\{\begin{array}{l}-+ \\
--\end{array}\right.$ & \pm & \pm+ & $=-$ & $=-$ & $\begin{array}{l}-1 \\
-3\end{array}$ & & 0,2 & - & - & - & - & - \\
\hline
\end{tabular}

deutlichen Bazillenbelag. Wenn man diese Kulturen weiter auf Meerschweinchen verimpft, findet man beim geimpften Tiere keine Tuberkulinreaktion, auch keine tuberkulösen Veränderungen bei der Sektion. Daraus sieht man klar, dass man hier keinen Tuberkelbazillus, sondern saprophytische säurefeste Bazillen vor sich hat.

Auch c) brachte wie a) und b) keine tuberkulösen Veränderungen hervor.

\section{Versuch 7 .}

Material : 5-12 Tage alter Typus humanus. Versuchstechnik ganz wie im 6. Versuch. Die mikroskopische und kulturelle Untersuchung des Filtrats endete negativ. Tierversuch: Impfung des Filtrats auf 2 Tiere, die des erhitzten Filtrats auf 1 Tier. Die Ergebnisse zeigt Tabelle III (d). Nach dieser Tabelle ist die Tuberkulinreaktion bei allen Tieren negativ. Man bemerkt keine Körpergewichtszunahme, auch keine besonderen Veränderungen.

\section{Versuch 8.}

7 Tage alte Kochsche avirulente Bazillen. Man emulgiert nach der gleichen Methode diese Bazillen mit physiologischer Kochsalzlösung, tut bazillus 
prodigiosus hinzu und filtriert sie durch $\mathrm{Chamberland} \mathrm{L3} \mathrm{unter} \mathrm{negativem}$ Druck von $30 \mathrm{~cm} \mathrm{Hg}$; Filtrationsdauer 30 Minuten. Die mikroskopische und kulturelle Untersuchung des so gewonnenen Filtrats endete negativ.

Tierversuch: Man impit das Filtrat auf 3 Tiere, das erhitzte Filtrat auf 1 Tier. Diese Ergebnisse sind in Tabelle III (e) verzeichnet.

Wie man aus der Tabelle ersieht, ist der Tuberkulinreaktion bei den mit Filtrat geimpften Ticren 2-6 Wochen lang schwach positiv, später negativ. Sonst alles negativ. Das Körpergewicht nimmt meistens zu. Tuberkulöse Veränderungen sind an den Organen nicht zu bemerken. Säurefeste Gebilde findet man nur bei dern mit erhitztem Filtrat geimpften Tier. Die Kultur säurefester Bazillen aus den Organen ist bei allen negativ. In diesen Versuchen habe ich also auch zur Zeit der Anfangsentwicklung kein filtrierbares Virus finden können.

\section{Tuberkulöse Sputa.}

(a) Sputum, in welchem Stäbchen massenhaft, Granula negativ, 1 Fall;

(b) Sputum, in welchem Stäbchen spärlich, Granula mässig, 2 Fälle und

(c) Sputum, in welchem Stäbchen negativ, Granula spärlich, 1 Fall.

Man lässt diese Spnta 2 Tage lang in einem Brutschrank bei $37^{\circ} \mathrm{C}$ stehen und Autolyse eintreten. Dann verdümnt man sie $10 \mathrm{fach}$ mit physiologischer Kochsalzlösung und filtriert sie durch Chamberland L3, nachdem man sie zuvor eimmal durch Papierfilter filtriert hat. Negativer Druck: $30 \mathrm{~cm} \mathrm{Hg.} \mathrm{Fil-}$ trationsdauer: 2-3 Stunden. Die mikroskopische und kulturelle Untersuchung des so gewonnenen Filtrats endete negativ. Die Tierversuche ergaben, was Tabelle IV ( $a, b, c)$ zeigt.

Unter den 3 mit Filtrat (a) geimpften Tieren fand man bei 2 schwach positive Tuberkulinreaktion, die bei einem Tier 2-8 Wochen lang erschien. Das Körpergewicht nahm zu. Man fand zwar keine tuberkulöse Veränderungen an den Organen, bei einem Tier jedoch säurefeste Gebilde, aber die Kultur endete negativ.

Unter den 5 mit Filtrat (b) geimpften Tieren nahm man bei 2 Fällen schwach positive Tuberkulinreaktion wahr (1-8 Wochen lang, nachher verschwunden). Bei den meisten Körpergewichtabnahme. Keine tuberkulöse Veränderung an den Organen. Alle mit Filtrat (c) geimpften Tiere starben an Pneumonie. Unter 2 mit diesem Filtrat geimpften Tieren bemerkte man bei $1(\mathrm{Nr} .90)$ säurefeste Gebilde, aber keine tuberkulöse Veränderung. Bei Nr. 90 fand ich nach 1 Monat gelbliche, feuchte Kolonien, ganz wie bei Nr. 46. Diese Befunde beweisen das Nichtrorhandensein filtrierbaren Tuberkulosevirus' im Sputurn. 


\section{E. Pleuraexsudat.}

Das filtrierbare Material wird genau, wie in der Methodik beschrieben, zubereitet. Negativer Druck $30 \mathrm{~cm} \mathrm{Hg}$. Filtrationsdauer 3 Stunden. Die mikroskopische und kulturelle Untersuchung des gewonnenen Filtrats endete negativ. Tierversuche ergaben, was Tabelle IV (d) zeigt. Sowohl 2 mit Filtrat geimpfte Tiere wie 1 mit erhitztem Filtrat geimpftes Tier zeigten negative Tuberkulimreaktion. Also konnte ich auch kein filtrierbares Tuberkulosevirus imi Exsudat finden.

F. Kochsche avirulente Bazillen.

Herkunft der Ko c h schen avirulenten Bazillen. Dieser Bazillenstamm soll von Herm F. G. Novy von Ann Arbor in den Vereinigten Staaten Amerikas 1888 aus Kochs Institut mitgebracht und in andauernder Kultur bis heute erhalten worden sein. Er soll von R obert Koch selbst rein gezüchtet worden sein. Dieser Bazillenstamm ist früher von the John Mc. Cormick-Institute for Infectious Diseases unserer Klinik überlassen und bei uns fortgezüchtet worden. Diese Bazillen können, ganz wie saprophytische, säurefeste Bazillen, in kurzer Zeit, in 1-2 Tagen, leicht auf Agar, Glyzerinagar und Nährböden für Tuberkelbazillen gedeihen.

Sie wurden 1, 3,5, 15 und 30 Tage lang auf Gingkoeiernährboden kultiviert, mit physiologischer Kochsalzlösung emulgiert und durch Chamberland L3 filtriert. Negativer $10-30 \mathrm{~cm} \mathrm{Hg.} \mathrm{Filtrationsdauer:}$ 10-30 Minuten. Wir versuchten dieses Filtrat wieder auf Gingkoeiernährboden zu kultivieren, hatten aber keinen Erfolg damit. Weiter gewannen wir aus ihnen 6 Monate lang kultivierte, ganz aus Granula bestehende Kulturen. Wir filtrierten sie wie üblich und versuchten das so gewonnene Filtrat zu kultivieren, doch gänzlich ohne Erfolg. Diese Granula gehen durch Kultur in 24 Stunden alle in 2-5 $\mu$ lange Stäbchen über. Dies beweist, dass Men sche Granula Chamberland L3 nicht passieren können.

G. Untersuchung der Tuberkulinallergie.

Nach den bisher von uns angestellten Tierversuchen, in denen bei 21 unter 45 mit Filtrat geimpften Tieren, d. h. bei $46,6 \%$, und bei 4 unter 13 mit erhitztem Filtrat geimpften Tieren, d. h. bei 33,3\%, die Tuberkulinreaktion schwach positiv auftrat, ist zu vermuten, dass diese Reaktion unspezifisch ist. Unter dieser Annahme führte ich noch folgende Untersuchung aus. 
Tabelle IV

Versuch mit dem Filtrat aus tuberkulösem

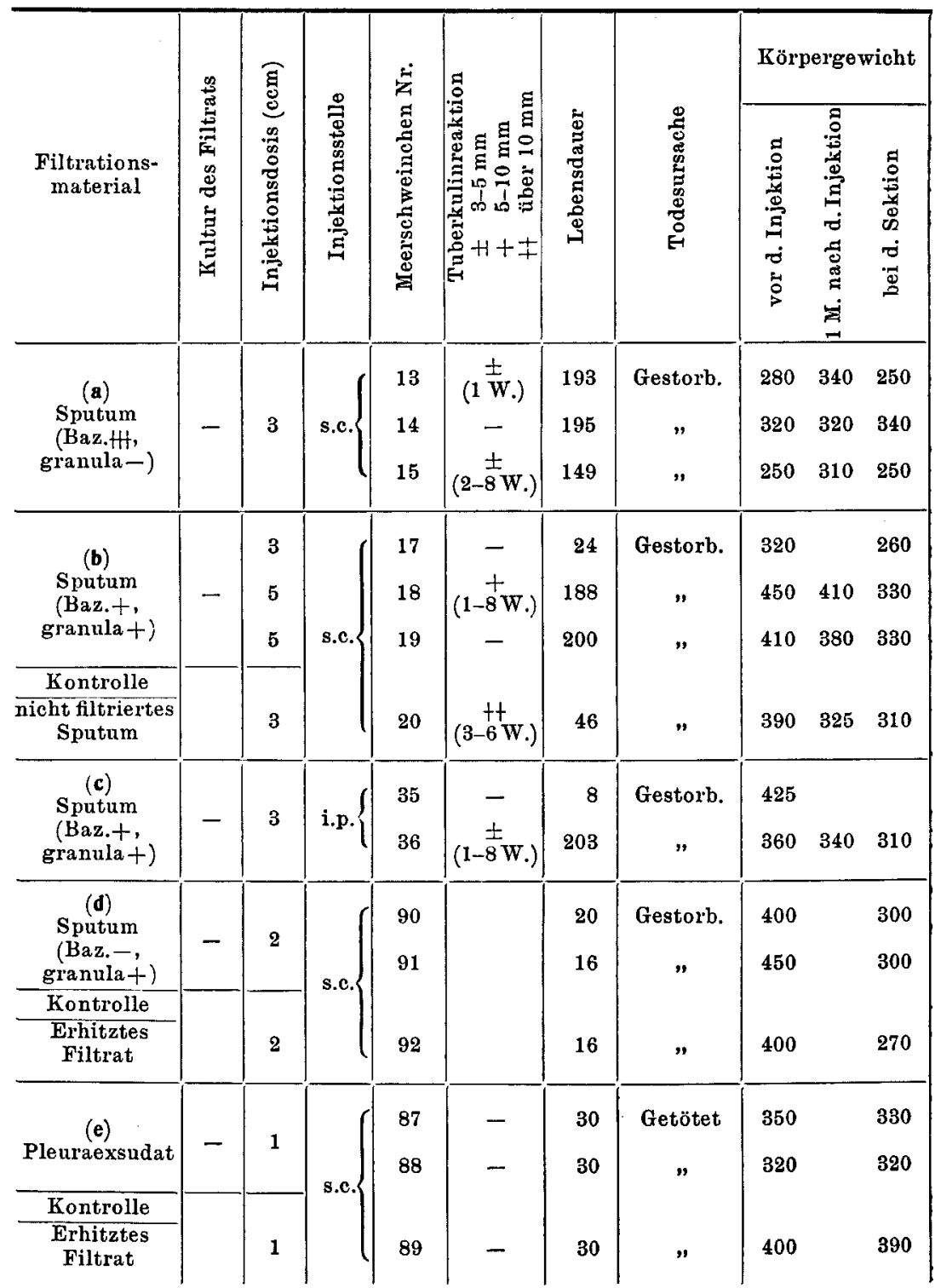


$(a, b, c, d, e)$.

Sputum und tuberkulösem Pleuraexsudat.

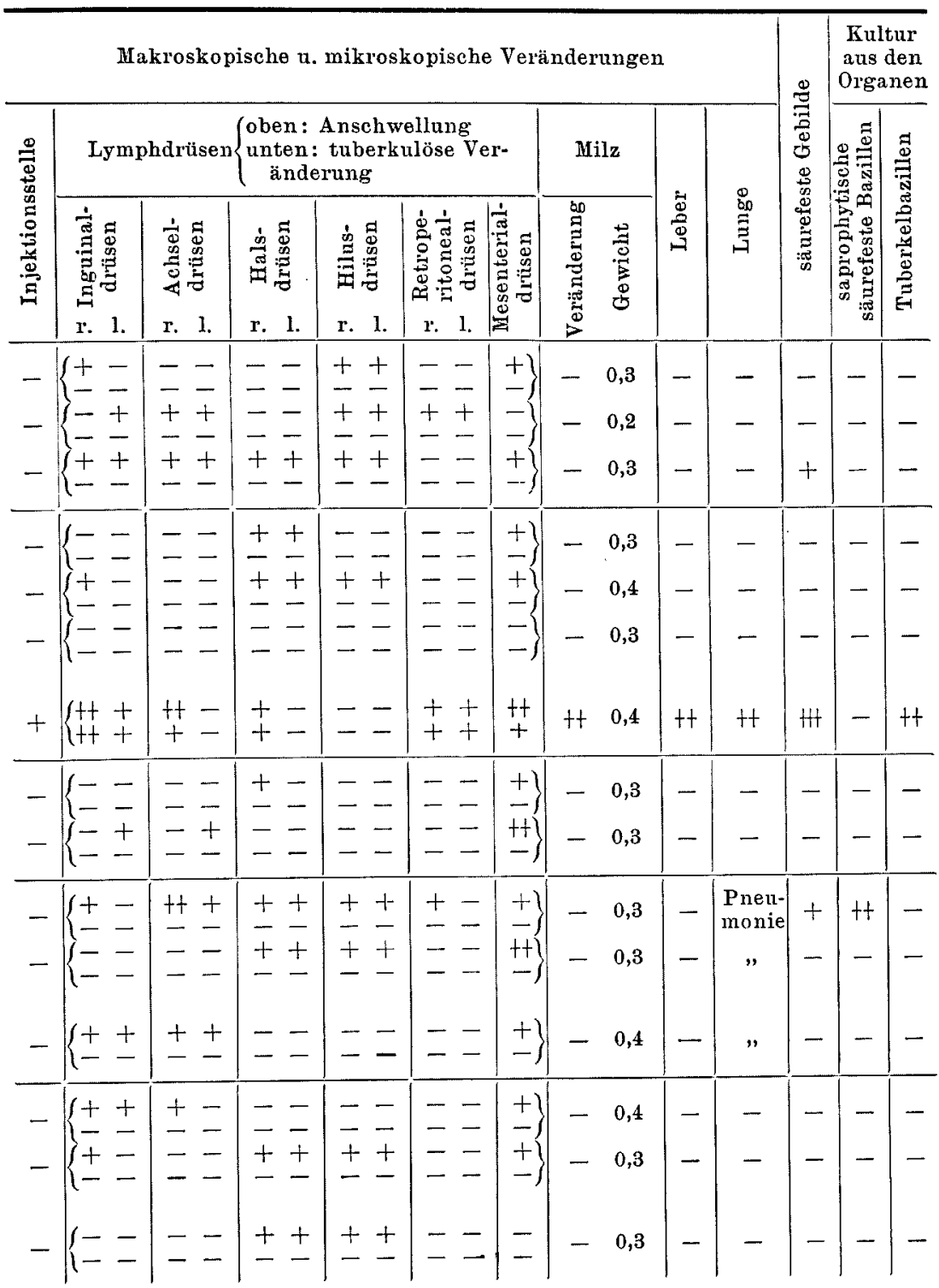


Durch Impfung von Alt-Tuberkulin, Alt-Tuberkulin + Schweineserum, albumosefreiem Tuberkulin, albumosefreiem Tuberkulin + Schweineserum, einer Organemulsion gesunder Meerschweinchen und

Tabelle

Untersuchung der

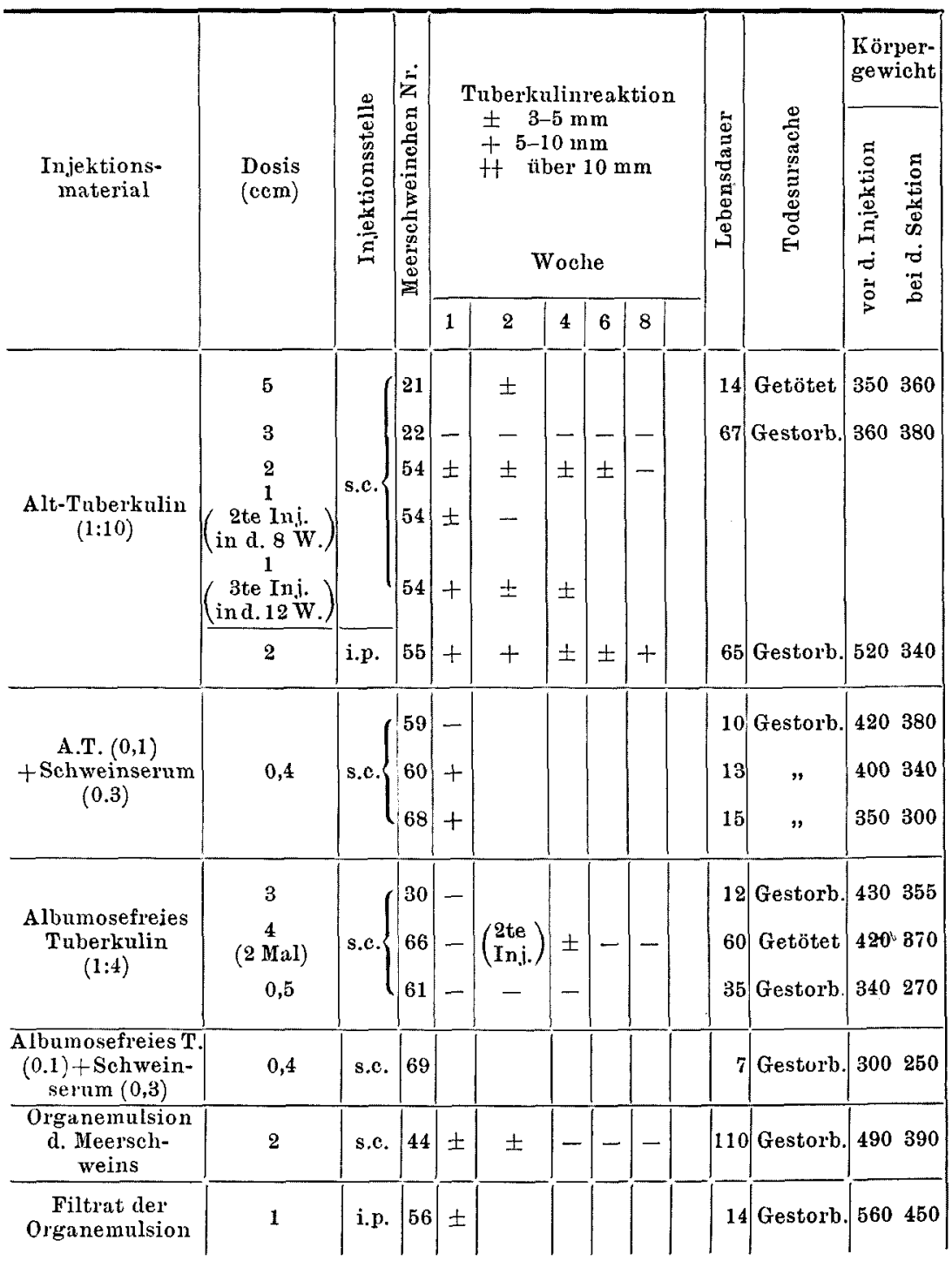


einem Filtrat dicser Emulsion auf Tiere habe ich die in Tabelle V wiedergegebenen Tuberkulinreaktionsergebnisse gewonnen.

Aus dieser Tabelle ersieht man, dass es möglich war, bei 8 unter

V.

Tuberkulinallergie.

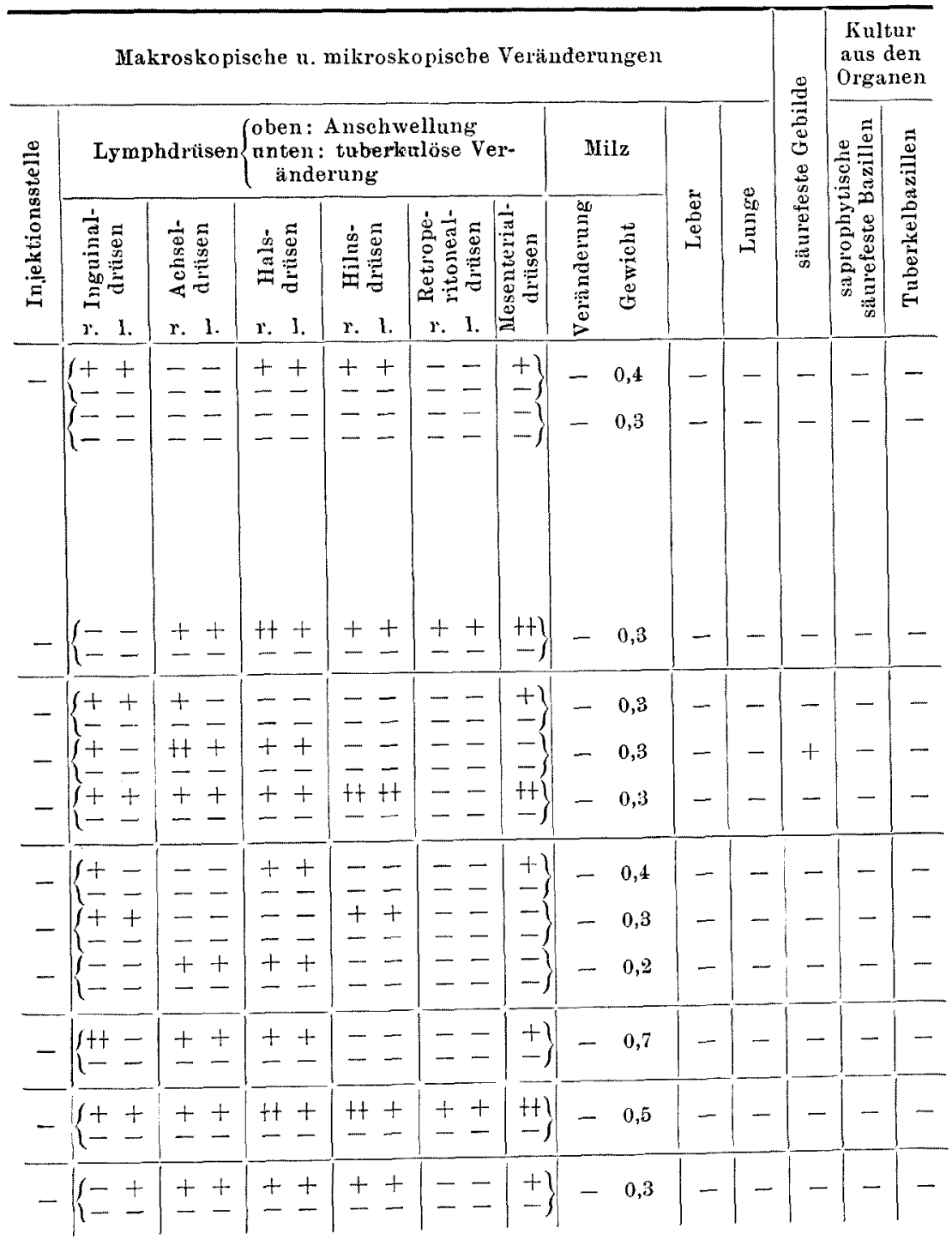


12 Tieren, d. h. bei $66 \%$, Tuberkulinallergie hervorzurufen. Bei Nr. 54 impfte man $2 \mathrm{ccm}$ Alt-Tuberkulin subkutan in den Oberschenkel des Tiers. Nach 1 Woche sah man eine $6 \times 6 \mathrm{qmm}$ grosse Rötung, nach 2 und 4 Wochen eine $4 \times 4$ qmm grosse und nach 6 Wochen nur noch eine Spur davon, nach 8 Wochen aber ist gar keine Reaktion mehr da. Dann impfte man in der 8. Woche wieder $1 \mathrm{ccm}$ Alt-Tuberkulin und bemerkte in der 9 . Woche eine $3 \times 3$ qmm breite Rötung, in der 11 Woche eine $2 \times 2 \mathrm{qmm}$ grosse. Man impfte noch einmal in der 12. Woche $1 \mathrm{ccm}$ und bekam eine Rötung von $5 \times 5 \mathrm{qmm}$ in der 13 Woche und eine von $4 \times 4 \mathrm{qmm}$ in der 17 Woche. Nach dieser Zeit herrscht die Neigung, allmählich zu verschwinden.

Albuminosefreies Tuberkulin zeigt sich nach einmaliger Impfung noch nicht allergisch, aber nach zwei Impfungen ganz schwach allergisch. Bei Organemulsion konnte ich auch festellen, dass das damit geimpfte Tier vorübergehend tuberkulinallergisch wurde. Unter den hier zu erwähnenden Tuberkulinallergien gab es einige, die schon in der 1 . Woche erschienen und bald wieder verschwanden, und auch andere, bei denen die Reaktion längere Zeit hindurch dauerte, aber keine, die über 6 Wochen dauerte. All diese Versuche stehen mit den von N. Os h ima in unserer Klinik ausgeführten Versuchen im grossen und ganzen im Einklang. Darauf wird später noch genauer eingegangen werden.

H. Untersuchungen durch Färbung der Organe gesunder und an unbekannten Krankheiten

gestorbener Meerschweinchen.

Ich fand bei 13 unter 45 mit Filtrat geimpften Meerschweinchen, d. h. bei $28,8 \%$, und bei 3 unter 13 mit erhitztem Filtrat geimpften Meerschweinchen, $d$. h. bei $23 \%$, tuberkelbazillenähnliche, säurefeste Granula und Stäbchen. Dann nahm ich die Organe 21 gesunder und der ohne jede Behandlung gestorbenen Meerschweinchen heraus, bereitete Strichpräparate davon, färbte sie und fand durch genaue Untersuchung bei 6 Tieren, $d$. h. bei $28,5 \%$, säurefeste Gebilde. Diese behandelte ich mit 5\% iger Schwefelsäure und kultivierte sie, konnte aber am Ende doch keine Reinkultur säurefester Bazillen gewinnen.

\section{Betrachtung.}

Beim Überblick über die Literatur lassen sich die Forscher, die das Vorhandensein filtrierbaren Tuberkulosevirus' bejahen, in zwei Gruppen einteilen. Die eine Gruppe umfasst solche Forscher, die die 
Existenz ultravisiblen, filtrierbaren Virus' betonen, wie Calmette, Valtis, Arloing, Dufourt, Ninni und andere Gelehrte der französischen Schule, sowie auch Rabino wits ch-K e mpner usw.. Demgegenüber stehen Forscher, die biologisch ultravisibles, filtrierbares Virus nicht anerkennen, sondern bloss zugestehen, dass Splitter oder Granula selten filtriert werden können. Zu dieser Gruppe gehören Lange u. Clauberg, Mellon u. Jost, ${ }^{58)}$ Lucksch, Keller u. Wethmar, ${ }^{59}$ Tomomatsu u. a. Die Veränderungen, die von diesen Forschern anerkannt werden, können wir, wie folgt, zusammenfassen:

1. Kachexie der mit Filtrat geimpften Tiere,

2. Leichte Positivität der Tuberkulinreaktion,

3. Lymphdrüsenanschwellung und

4. Auftreten säurefester Bazillen in den Organen, besonders in den Lymphdrüsen; übrigens ist es kein histologischer Tuberkel. Sind solche Veränderungen wie diese wirklich imstande, das Vorhandensein ultravisiblen, filtrierbaren Tuberkulosevirus' zu beweisen?

Ich möchte im folgenden, die Ergebnisse meiner Versuche zusammenfassend, diese Frage betrachten.

\section{Kachexieder mit Filtrat geimpften Tiere.}

Nach meinen Beobachtungen gibt es ziemlich viele Versuchstiere, deren Körpergewicht 1 Monat nach der Impfung des Filtrats abnahm. Diese Abnahme ist je nach der Art des Filtrats verschieden. Bei den einen Filtraten ist sie sehr beträchtlich, bei den anderen gering, und bei wieder anderen sieht man überhaupt keine Gewichtsabnahme. Tiere, die mit derselben Art von Filtrat behandelt werden, zeigen ungefähr den gleichen Verlauf. Auch wenn man jedes Filtrat erhitzt und den Tieren solch erhitztes Filtrat einspritzt, so sieht man die entsprechende $A b$ - oder Zunahme des Körpergewichts, ganz wie beim ursprünglichen Filtrat.

Daraus erkennt man, dass die Filtrate von ihrem Stoff her verschiedene Toxizität besitzen und ihr Erhitzen ihre Wirkung gar nicht verändert. Also kann man in den Filtraten kein lebendes Agens erblicken. Auch beim Einspritzen von Tuberkulin nimmt man die gleiche Körpergewichtsabnahme wahr.

Deshalb meine ich, wie Montemartini, Capuani, Pinner und Voldrich, Szüle u. a., dass die Kachexie durch Tuberbulin hervorgebracht wird.

2. Positive Umwandlung der Tuberkulinreaktion.

Dass sich die Tuberkulinreaktion durch Impfung des Filtrats 
positiv umwandelt, ist von vielen Forschern anerkannt. Rabinowitsch-Kempner stellten experimentell fest, dass sie umgefähr nach 1 Woche schwach positiv wurde und bald darauf verschwand. Sie führen das auf schwache Virulenz zurück.

Es gab aber andererseits schon früher Untersuchungen von Capelle ${ }^{(0)}$ (1911), Mantoux u. Perroy ${ }^{61)}$ (1911) über unspezifische Tuberkulinallergie. Und in neuerer Zeit ist von Moro u. Kelle $r^{62)}$ (1925), Gröer, Progulski u. Redlich ${ }^{63)}$ (1926), Adam ${ }^{64)}$ (1926), Kirchner (1930), Szüle (1931), Oshima, $\left.{ }^{6 \bar{j}}\right)$ Reichle u. Goldb lat ${ }^{66)}(1932)$ u. a. festgestellt worden, dass Tuberkulinreaktion auch durch Einspritzen von abgetöten Tuberkelbazillen, Tuberkulin, Tuberkulin mit Kuhpockenlymphe, Sch weineserum, Timothee-Bazillen, Organemulsion, Ölextrakt von Tuberkelbazillen usw. hervorgebracht werden kann. Oshima hat gefunden, dass diese unspezifische Tuberkulinreaktion im frühen Stadium eintritt und binnen 8 Wochen versch windet.

Unsere Versuche zeigten, dass bei 20 unter 45 mit Filtrat geimpften Meerschweinchen, d. h. bei $44,4 \%$, bei 3 unter 13 mit erhitztem Filtrat geimpften Meerschweinchen, d. h. bei $23 \%$, und ferner bei 8 unter 12 mit Alt-Tuberkulin, Alt-Tuberkulin + Schweineserum, albumosefreiem Tuberkulin, Organemulsion von Meerschweinchen und dem Filtrat dieser Emulsion geimpften Tieren, d. h. bei $66,6 \%$, die Tuberkulinreaktion schwach positive Umwandelung zeigte. Von diesen Reaktionen traten einige schon in der ersten Woche ein, und die am längsten dauernde dehnte sich bis zur 8. Woche aus. Nach dieser Zeit wurden sie alle negativ. Diese Ergebnisse zeigen uns, dass die durch das Filtrat tuberkulösen Stoffes hervorgerufene Tuberkulinallergie wahrscheinlich nichts anderes als die durch Einspritzung von Tuberkulin oder fremdem Eiweiss verursachte Parallergie (Moro) oder heterogenetische Tuberkulinreaktion (Ada m) ist und nicht ohne weiteres als Reaktion auf ultravisibles, filtrierbares Virus angesehen werden kann.

\section{Lymphdrüsenanschwellung.}

Lymphdrüsenanschwellung wird häufig bei den an unbekannten Krankheiten gestorbenen Meerschweinchen gefunden. Hababou$\mathrm{Sala}^{67}(1928)$ stellte durch Experiment fest, dass die Lymphdrüsen eine starke Affinität zum Tuberkulin haben und dass Lymphdrüsenanschwellung deutlich durch Tuberkulin hervorgebracht wird. Saenz u. Deins $\left.{ }^{68}\right)(1928)$ haben durch Versuch gefunden, dass die Einspritzung vollkommen sterilen Tuberkulins. bei Tieren Anschwellung entfernter Lymphdrüsen hervorruft und dass abgetötete Tuberkelbazillen 
enthaltendes Tuberkulin Lymphdrüsenanschwellung gerade am gespritzten Teil hervorbringt.

In unseren Versuchen haben wir bei den meisten Tieren durch Impfung frischen wie auch erhitzten Filtrats leichte Lymphdrüsenanschwellung bemerkt, aber keinen bemerkenswerten Unterschied je nach der Art des Filtratmaterials. Histologisch bemerkte ich $\mathrm{Hy}-$ perämie, Randsinuskatarrh und Anschwellung des retikuloendothelialen Systems, eine Erscheinung der Lymphadenitis. Man kann aber diese Veränderungen wohl auf das Toxin zurückführen. Die gleichen Veränderungen bemerkte ich auch bei Einspritzung von Tuberkulin.

\section{Vorhandensein säurefester Gebilde.}

Die für das Vorhandensein filtrierbaren Virus' eintretenden Gelehrten legen den Hauptwert auf den Nachweis, dass bei den mit Filtrat geimpften Tieren säurefeste Bazillen oder Granula zu finden seien. Aber diese Bazillen bilden keine Tuberkeln, und ihre Kultur endet in den meisten Fällen erforglos. Auch bezüglich der Virulenzsteigerung. durch Tierpassage herrscht keine Übereinstimmung in den Versuchsergebnissen der verschiedenen Forscher. Dein s $\mathrm{e}^{(\mathrm{i})}$ behauptet, dass er durch 4-malige Tierpassage typische Tuberkulose erzeugt habe. Das wird aber von Rabinowitsch-Kempner, Togounoff, Valtis, Nègre Boquet u. Certonciny u. a. nicht anerkannt. Sind nun solche säurefeste Bazillen wirklich Tuberkelbazillen? Dass es überall in der Natur vielerlei saprophytische süurefeste Bazillen gibt, ist seit langem von vielen Gelehrten anerkannt worden. Sie kommen unter anderem in Leitungswasser, Erde, Trompete, Kot, Harn, Smegma, Butter usw. vor. Kürzlich kultivierte Otaw a ra $a^{\text {in) }}$ säurefeste Bazillen zu $65 \%$ in der Erde, zu $100 \%$ im Abzugswasser, zu $63,9 \%$ im Leitungswasser und zu $46 \%$ im Kot von Tieren.

Wir müssen solche säurefeste Bazillen immer als Fehlerquelle im Auge haben. $\mathrm{Kahn}^{71)}$ stellte die Säurefestigkeit von Lecithin und Cholesterin, van Giesen ${ }^{72)}$ die der Fettkörper fest, und sie warnten vor deren Verwechselung mit Tuberkelbazillen.

Ferner ist es ein scliwieriges Problem, ob die saprophytischen säurefesten Bazillen in den Organen der Meerschweinchen spontan vorhanden sind oder nicht. K $\mathrm{K} l \mathrm{be}^{233}$ und Sel te $\mathrm{r}^{24)}$ fanden viele Mikroorganismen in den Lungen und den Bronchialdrüsen normaler Tiere. Thieringer ${ }^{75)}$ Hoebel, ${ }^{76)}$ Simons, ${ }^{77)}$ Otawara u.a. entdeckten saprophytische säurefeste Bazillen im Kot von Rindern, Mäusen, Pferden, Kaninchen, Hunden, Meerschweinchen usw. Nélis und Baeckel ${ }^{8)}$ (1928) gaben jungen Meerschweinchen per os Paratuber- 
kelbazillen und wiesen nach einigen Stunden diese Bazillen in ihren Lymphdrüsen nach.

Rabinowitsch-Kempner, Sanctis Monaldi, Lange u. Clauberg fanden zwar bei Meerschweinchen keine spontane Infektion durch saprophytische säurefeste Bazillen, Selter u. Blumenberg aber bei $\frac{1}{3}$ und Cooper und Petroff bei $33 \%$. Thounson und Frobischer, Szüle u. a. stimmen den letzten bei. Bei meinen Versuchen fand ich bei 13 unter 45 mit Filtrat geimpften Tieren, d. h. bei $28,8 \%$, bei 3 unter 13 mit erhitztem Filtrat geimpften Tieren, d. h. bei $23 \%$, und bei 6 unter 21 gänzlich unbehandelten Meerschweinchen, d. h. bei $28,5 \%$, säurefeste Gebilde. Und bei 4 unter diesen Tieren konnte ich die Reinkultur saprophytischer säurefester Bazillen erhalten. Ferner habe ich aus Leitungswasser säurefeste Bazillen bekommen, die eine ganz älnnliche gelbliche Kolonie zeigten, und auch aus dem im Tierstall benutzten Stroh säurefeste Bazillen, die eine weisslich und gelbliche feuchte Kolonie bildete. Es ist ganz natürlich, dass diese saprophytische säurefesten Bazillen immer von den Tieren durch das Maul aus Gras, Stroh, Erde, Wasser usw. aufgenommen werden, und es lässt sich leicht denken, dass sie dann bald in die Lymph- und Blutbahn eindringen können.

Bei der Färbung zeigten sie schwache Säurefestigkeit, und diejenigen, die sich kultivieren liessen, waren meistens stärker säurefeste Stäbchen. Das komint wahrscheinlich daher, dass die meisten Bazillen durch die Behandlung mit Schwefelsäure starben und darum einen niedrigen Kulturprozentsatz ergaben.

Ferner berichten Valtis und Deins $\mathrm{e}^{\mathrm{ig})}$ (1932), dass sie aus den mit Filtrat geimpften Tieren Bazillenreinkultur gewonnen hätten. Das filtrierte Material habe zum Typus bovinus und die gewonne Kultur zum Typus gallinaceus gehört. Danach meinten sie, dass Bazillen im filtrierbaren Stadium labil seien und dass der Typus bovinus in den Typus gallinaceus übergehe. Ich halte es aber für wahrscheinlicher, dass hier eine spontane Infektion vorliegi.

\section{5. Über die Filtrierbarkeit der Granula.}

Ich benutzte eine Kultur ganz aus Granula bestehender avirulenter Bazillen Kochs. Obwohl sich alle diese Granula, wie schon oben bemerkt, in 24 Stunden zu Stäbchen entwickelten, so endete die Kultur ihres Filtrats durch Chamberland Li3 trotz wiederholter Versuche doch durchaus negativ. Daraus folgt mit Sicherheit, dass die Granula von Tuberkelbazillen unter normalen Verhältnissen niemals Chamberland L3 passieren. 


\section{Zusammenfassung.}

(1) Die Kachexie des mit Filtrat tuberkulösen Materials geimpften Tiers ruihrt vom Tuberkulin her.

(2) Die durch Impfung des Filtrats hervorgerufene Tuberkulinallergie ist nicht ohne weiteres als spezifisch anzusehen; sie ist wahrscheinlich eine unspezifische.

(3) Die Lymphdrüsenanschwellung des mit Filtrat geimpften Tier's rührt auch von Tuberkulin oder fremdem Eiweiss her.

(4) Während einerseits in den Organen der mit dem Filtrat geimpften Meerschweinchen zu 28,8\% säurefeste Gebilde gefunden wurden, so liessen sie sich anderseits doch auch bei $28,5 \%$ normaler Meerschweinchen nachweisen.

(5) Es ist unmöglich, durch Impfung des Filtrats mikroskopisch oder makroskopisch Tuberkel zu erzeugen.

(6) Deshalb kann ich das Vorhandensein ultravisiblen, filtrierbaren Tuberkulosevirus' nicht bestätigen.

Die Kosten für diese Untersuchung sind von der Saito Hōonkai Stiftung bestritten worden, wofür ich hier meinen besten Dank ausspreche.

Prof. Dr. T. Kumagai.

\section{Literatur.}

(1) Spengler, Zeitsclır. Hyg., 1905, 49, 541.

(2) M u c h, Beitr. Klin. Tbk., 1907, 8, 85.

(3) Fontés, Wien. med. Wschr., 1926, 1050.

(4) P hilibert, zit. nach $B$ I u men berg (Ergebnisse der gesamten Tuberkuloseforschung $\mathrm{Bd}$. II. Leipzig 1931, 14).

(5) Vaudremer, C. r. Soc. Biol., 1923, 89, 80.

(6) Handuroy u. Vaudremer, C. r. Soc. Biol., 1923, 89, 1276.

(7) Valtis, C. r. Soc. Biol., 1924, 90, 1130.

(8) V a n nucci, Ref. Zbl. f. gesamt. Tbk-forschung, 1925, 23, 40.

(9) Ve ber, C. r. Soc. Biol., 1926, 94, 8.

(10) Arloing, Dufourtu. Malartre, C.r. Soc. Biol., 1926. 94, 46.

(11) Nélis, C. r. Soc. Biol., 1927, 96, 21.

(12) Valtis, Negre, Boquet u. Certonciny, C. r. Soc. Biol., 1927, 97, 1667.

(13) Togonnoff, C. r. Soc. Biol., 1927, 97, 547.

(14) Bonciu u. Jonesco, C.r. Soc. Biol., 1928, 98, 464.

(15) Rabinowitsch-Kem puer, Zeitschr. Tbk., 1928, 52, 18.

(16) Sweany, Amer. Rev. Tbc., 1928, 17, 53.

(17) Priboiano u. Lacomme, C. r. Soc. Biol., 1929, 100, 402.

(18) Is a bolinski u. Gitowitseh, Immun-forschung, 1929, 63, 510.

(19) V a s c ella ri, Ref. Zbl. f. gesamt. Tbk-forschg., 1930, 33, 661.

(20) S a narelli u. Aless and ri ni, Ref. Zbl.f. gesamt. Tbk-forschg. 1932, 36, 394.

(21) Sanctis Monaldi, Ref. Zbl. f. gesamt. Tbk-forschg. 1931, 34, 441.

(22) Cuturi u. Lanza, Ref. Zbl. f. gesamt. Tbk-forsehg. 1932, 36, 394. 
(23) Luckse h, Zbl. Bakt. I., Orig., 1930, 117, 1.

(24) Calmette, Dtsch. med. Wschr., 1928, 1995.

(25) do, Dtsch. med. Wschr., 1930, 733.

(26) Calmette u. Valtis, Zeitschr. Tbk., 1930, 58, 402.

(27) Valtis u. Sainz, C. r. Soc. Biol., 1930, 103, 134.

(28) Ninn i, C. r. Soc. Biol., 1930, 103, 891.

(29) Do, C. r. Soc. Biol., 1932, 110, 169.

(30) L a n za, Ref. Zbl. f. gesamt. Tbk-forsehg. 1932, 32, 694 .

(31) Puca, C. r. Soc. Biol., 1932, 111, 258.

(32) Fes s le r, Zbl. Bakt. I., Orig., 1926, 98, 148.

(33) N a kajo, Jap. Med. World, 1929, 8, 120

(34) Montemartini, Ref. Zbl. f. gesamt. Tbk-forschg., 1925, 24, 706.

(35) Bettini, ibid., 1932, 36, 70.

(36) Capnani, ibid, 1931, 35, 639.

(37) Co oper n. Petroff, J. Inf. Dis., 1928, 43, 200.

(38) Lindemann u. Li, Beitr. Klin. Tbk., 1928, 70, 380.

(39) Morosowa, Zbl. Bakt. I., Orig., 1929, 113, 200.

(40) Thompson u. Frobischer, Amer. Rev. Tbc., 1928, 18, 832.

(41) Löwenstein u. Singer, Wien. klin. Wschr., 1929, 1341.

(42) Selter u. Blumen berg, Zbl. Bakt. I., Orig., 1929, 110, 167.

(43) Lange u. Cla n berg, Zeitschr. Tbk., 1929, 53, 1.

(44) Kirchner, Beitr. Klin. Tbk., 1930, 74, 521.

(45) Le usden, Zeitschr. Tbk., 1930, 55, 437.

(46) Se hmidt, Zeitschr. Hyg., 1931, 112, 95.

(47) Petragnani, Ref. Zbl. f. gesamt. Tbk-forschg., 1929, 31, 50.

(48) Sz üle, Beitr. Klin. Tbk., 1931, 78, 18.

(49) Pinneru. Voldrich, Amer. Rev. Tbe., 1931, 24, 73.

(50) Yosh in ag a u. Endo, Tokyo Izishinshi, 1926, 2375.

(51) Miyamoto, Kekkaku, 1928, 6, 645.

(52) N a k ag a w a, Hokkaido Igaku Zasshi, 1932, 10, 449.

(53) Maeda u. S umikawa, Saikingaku Zasshi, 1927, 271.

(54) Nishimoto, Nihon no Ikai, 1928, 18, 8.

(55) To mo matsu, Osaka Igakukai Zasshi, 1932, 31, 1427.

(56) Suzuki, Tohoku Journ. exp. Hed., 1934, 23, im Erscheinen.

(57) M. C. Kahn, Amer. Rev. Tbe., 1928, 18, 815.

(58) Mellon u. Jost, Amer. Rev. Tbe., 1929, 19, 483.

(59) Keller u. Wethma1', Zeitschr. Tbk., 1929, 54, 22.

(60) Ca pelle, Zbl. Bakt. I., Orig., 1911, 60, 531.

(61) Mantoux u. Perroy, C. r. Soc. Biol., 1911, 70, 974.

(62) Morou. Keller, Dtsch. med. Wschr., 1925, 1015.

(63) Gröex, Progulski u. Redlich, Klin. Wschr., 1926, 414.

(64) A d a m, Beitr. klin. Tbk., 1926, 63, 635 .

(65) Reichle u. Goldblatt, Amer. Rev. Tbc., 1932, 27, 291.

(66) Oshima, Tohoku-Igaku-Zasshi, 1933, 16, 157.

(67) H a ba bou-S a la, C. x. Soc. Biol, 1928, 99, 1217.

(68) Saenz u. Deinse, C. r. Soc. Biol., 1928, 99, 1940.

(69) Deinse, C. r. Soc. Biol,, 1929, 101, 273.

(70) Otaw ara, Tokyo Ijishinshi, 1933, 363.

(71) E. K a hn, Münoh. med. Wschr., 1913,345.

(72) van Giesen, Zbl. Bakt. I., Ref., 1912, 55, 530.

(73) Kälbe, Münch. med. Wschr., 1899, 622.

(74) Selter, Zeitschr. Hyg., 1906, 54, 363.

(75) Thieringer, zit. nach Blumenberg (Ergebnisse der gesamten Tuberkuloseforschung Bd. II. Leipzig 1931, 60.)

(76) Hoebel, zit. nach Blume nberg (ibid. 60.)

(77) Sim ons, J. inf. Dis,, 1917, 41, 13.

(78) Nélis u. Boeckel, C. r. Soc. Biol., 1928, 99, 1251.

(79) Valtis u. Deinse, C. r. Soc. Biol., 1932, 111, 371. 